\title{
Redox-dependent chaperone/peroxidase function of 2-Cys-Prx from the cyanobacterium Anabaena PCC7120: role in oxidative stress tolerance
}

\author{
Manisha Banerjee, Dhiman Chakravarty and Anand Ballal
}

\begin{abstract}
Background: Cyanobacteria, progenitors of plant chloroplasts, provide a suitable model system for plants to study adaptation towards different abiotic stresses. Genome of the filamentous, heterocystous, nitrogen-fixing cyanobacterium Anabaena PCC7120 harbours a single gene (alr4641) encoding a typical 2-Cys-Peroxiredoxins (2-Cys-Prxs). 2-Cys-Prxs are thiol-based peroxidases that also function as molecular chaperones in plants and other systems. The Alr4641 protein from Anabaena PCC7120 shows high level biochemical similarities with the plant 2-Cys-Prx. The physiological role played by the Alr4641 protein in Anabaena was addressed in this study.

Results: In Anabaena PCC7120, alr4641 transcript /Alr4641 protein was induced in response to abiotic stresses and its promoter was active in the vegetative cells as well as heterocysts. The wild-type Alr4641 protein or Alr4641 lacking the peroxidatic cysteine (Alr4641C56S) or the resolving cysteine (Alr4641C178S) existed as higher oligomers in their native form. The wild-type or the mutant Alr4641 proteins showed similar chaperone activity, but only the wild-type protein exhibited peroxidase activity indicating that unlike peroxidase activity, chaperone activity was not dependent on cysteines. In contrast to other 2-Cys-Prxs, chaperone/peroxidase activity of Alr4641 was dependent on its redox state and not oligomerization status. Alr4641 could protect plasmid DNA from oxidative damage and physically associate with NADPH-dependent thioredoxin reductase (NTRC). Like 2-Cys-Prxs from plants (e.g. rice), Alr4641 could detoxify various peroxides using NTRC as reductant. On exposure to $\mathrm{H}_{2} \mathrm{O}_{2}$, recombinant Anabaena PCC7120 strain over-expressing Alr4641 $\left(A n 4641^{+}\right)$showed reduced content of reactive oxygen species (ROS), intact photosynthetic functions and consequently better survival than the wild-type Anabaena PCC7120, indicating that Alr4641 can protect Anabaena from oxidative stress.

Conclusions: The peroxidase/chaperone function of Alr4641, its inherent transcriptional/translational induction under different abiotic stresses and localization in both vegetative cells and heterocysts could be an adaptive strategy to battle various oxidative stresses that Anabaena encounters during its growth. Moreover, the recombinant Anabaena strain over expressing Alr4641 showed higher resistance to oxidative stress, suggesting its potential to serve as stress-tolerant biofertilizers in rice fields.
\end{abstract}

\section{Background}

Peroxiredoxins (Prxs) are ubiquitous peroxidases with important roles in detoxification of hydrogen peroxide, alkyl hydroperoxides and peroxynitrites [1,2]. Prxs are characterized by a conserved Alkylhydroperoxide C (AhpC) or Thiol-Specific Antioxidant (TSA) domain that contains a thioredoxin fold. Prxs have highly conserved cysteine residues, peroxidatic cysteine $(\mathrm{Cp})$ and resolving cysteine

\footnotetext{
* Correspondence: aballal@barc.gov.in

Molecular Biology Division, Bhabha Atomic Research Centre, Mumbai 400085,
} India

\section{Biomed Central}

(Cr), which are essential for peroxidase activity. Based on their catalytic mechanisms and the presence of conserved cysteine residues, Prxs are classified into three groups, namely, typical 2-Cys-Prx, atypical 2-Cys Prx (which are subdivided into type II Prx and PrxQ) and 1-Cys-Prx [3].

The typical 2-Cys-Prxs are functionally conserved across diverse organisms and form the largest group of peroxiredoxins. Recently, 2-Cys-Prx has been shown to be a conserved marker of circadian rhythms in all the three phylogenetic domains viz. Eukaryota, Bacteria and Archaea [4]. In typical 2-Cys-Prxs, $\mathrm{Cp}$ is present near N-terminus 
while $\mathrm{Cr}$ is located in the vicinity of $\mathrm{C}$-terminus. On reaction with a peroxide substrate, $\mathrm{Cp}$ (Cys-SH) is oxidized to sulfenic acid (Cys-SOH), which in turn reacts with the thiol group of the resolving cysteine from other subunit to form an intermolecular disulfide bridge [5]. The active form of enzyme is regenerated with the help of reductants like thioredoxin. In the presence of excess substrate (e.g. $\mathrm{H}_{2} \mathrm{O}_{2}$ ), Cp of 2-Cys-Prx may undergo overoxidation to form sulfinic acid $\left(\mathrm{Cys}-\mathrm{SO}_{3}\right)$, which prevents disulfide bond formation, rendering the enzyme inactive. However, in many organisms, sulfiredoxin (Srx) reduces the overoxidized $\mathrm{Cp}$ to its catalytically active form [6,7]. Sensitivity to overoxidation depends on the structural motifs, GG(L/V/I)G and YF, which are believed to be present in the eukaryotic 2-Cys-Prxs, but generally absent in the corresponding prokaryotic enzymes [8].

The typical 2-Cys-Prx plays a vital role in detoxifying peroxides in all the kingdoms of life. Transgenic Arabidopsis with decreased 2-Cys-Prx in chloroplast showed oxidative damage of chloroplastid proteins indicating that 2-Cys-Prx protects the photosynthetic machinery from oxidative damage $[9,10]$. Also, Arabidopsis mutant lacking both the chloroplastid 2-Cys-Prx displayed altered redox homeostasis and showed increased $\mathrm{H}_{2} \mathrm{O}_{2}$ levels in leaves [11]. Overexpression of 2-Cys-Prx has been shown to protect potato plants from oxidative stress and high temperature [12]. In tobacco, the chloroplastid 2-Cys-Prx has been implicated in protecting cells from photoinhibition following exposure to high light, methyl viologen (MV) or t-butyl hydroperoxide [13]. Disruption of gene encoding 2-Cys-Prx in Synechocystis as well as in Synechococcus eliminated tolerance against $\mathrm{H}_{2} \mathrm{O}_{2}[14,15]$. In bacteria like Sulfolobus solfataricus and Vibrio vulnificus, 2-Cys-Prx has been proposed to detoxify endogenously generated hydrogen peroxide, thus, supporting its role as an anti-oxidative stress protein [16,17].

Interestingly, the typical 2-Cys-Prx not only defends cells from oxidative stress, but also functions as redox-regulated chaperone depending on its oligomerization status [18]. The 2-Cys Prx from Pseudomonas aeruginosa, on exposure to $\mathrm{H}_{2} \mathrm{O}_{2}$, converts into a low molecular weight (LMW) form from its high molecular weight (HMW) form. This change triggers a chaperone to peroxidase functional switch [19]. In case of 2-Cys Prx from yeast, oxidative stress and heat shock triggers conversion from LMW form to HMW structure, which shows chaperone activity [20]. In stroma of chloroplast, under conditions of stress, the dimeric 2-Cys-Prx switches to its oligomeric form and binds reversibly to the thylakoid membrane [21]. It is widely believed that the dimeric form of 2-Cys-Prx shows peroxidatic functions while oligomerization is essential for chaperone activity [2].

Cyanobacteria, progenitors of plant chloroplasts, were the first organisms to produce oxygen as a by-product of photosynthesis [22,23]. Hence, it is expected that these organisms would have developed elaborate mechanisms to overcome oxidative stress. Filamentous forms of nitrogenfixing cyanobacteria (e.g. Anabaena) are economically important as biofertilizers during cultivation of paddy in Southeast Asia [24]. Anabaena PCC7120, a filamentous, heterocystous, diazotrophic cyanobacterium, that tolerates abiotic stresses like radiation and desiccation, has been used as a suitable model system to study the fundamental aspects of adaptive responses to various stresses including oxidative stress in our laboratory [25-29]. Genome sequence analysis has shown Anabaena PCC7120 to possess several peroxiredoxin genes/ORFs (e.g. all1541, alr2503, all2375, all2556, alr3183, alr4404, alr4642 and alr4641) [30]. The Alr3183, Alr2503, All2375 and All2556 belong to PrxQ-type of peroxiredoxins, All1541 is a type II Prx, Alr4404 is a 1-Cys-Prx, Alr4642 is Prx-like, whereas Alr4641 is a typical 2-Cys-Prx [26,31].

Earlier, 2-Cys-Prx from Anabaena was shown to be prone to over-oxidation [8] and was found to utilize $\mathrm{NADPH}$-dependent thioredoxin reductase (NTRC) as reducing agent for peroxidase activity like the 2-Cys-Prx from rice [32]. In this study, expression analysis in response to various stresses, redox dependent chaperone/peroxidase function and the role played by this enzyme in protecting Anabaena from oxidative stress were addressed. Along with oxidative stress, alr4641/Alr4641 was induced by salt/osmotic/ $\gamma$-radiation stress in Anabaena and the Alr4641 protein was expressed in the vegetative cells as well as heterocysts. Alr4641 formed higher oligomeric complexes and showed peroxidase/chaperone function. Unlike peroxidase activity, chaperone activity of Alr4641 did not depend on the conserved cysteine residues. Interestingly, reduction of Alr4641 with DTT resulted in loss of chaperone activity whereas treatment with $\mathrm{H}_{2} \mathrm{O}_{2}$ inactivated peroxidase function. Over-expression of Alr4641 in Anabaena protected the photosynthetic machinery from $\mathrm{H}_{2} \mathrm{O}_{2}$-induced damage via its peroxidatic cysteine, leading to better survival than the wild-type Anabaena; thus, establishing its protective role in overcoming oxidative stress.

\section{Results}

\section{Abiotic stresses induce alr4641/Alr4641 expression in Anabaena}

Expression of alr4641 in response to different oxidative stress inducing agents was assessed by Northern blottinghybridization/dot blot analysis. The wild-type Anabaena PCC7120 cells were treated with methyl viologen (MV), hydrogen peroxide $\left(\mathrm{H}_{2} \mathrm{O}_{2}\right)$ or tertiary butyl hydroperoxide $(t-B x)$ for $1 \mathrm{~h}$. Subsequently, cells were harvested, total RNA isolated and probed with the alr4641 gene probe. Results showed distinct induction of 0.9-knt transcript in RNA isolated from Anabaena cells exposed to the above-mentioned oxidizing agents as compared to the untreated (control) cells (Figure 1A). 
A

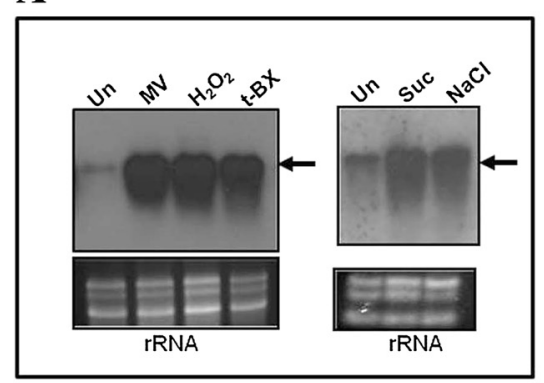

B

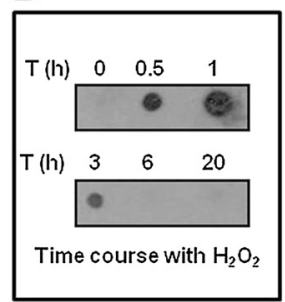

C

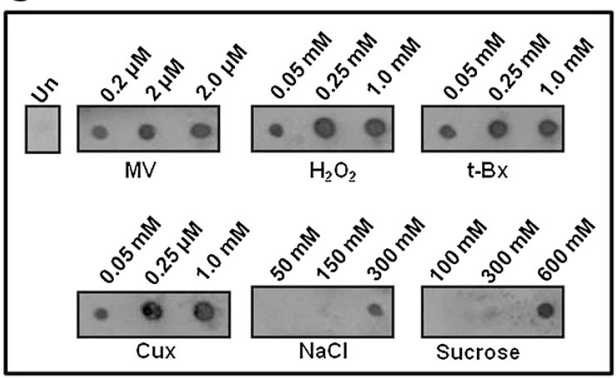

E

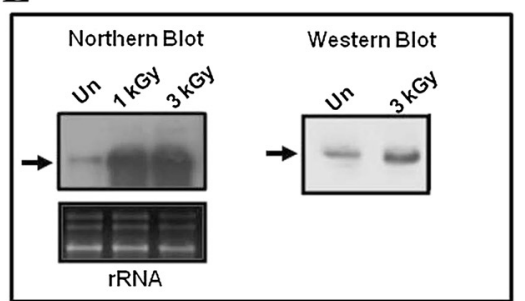

Figure 1 Induction of alr4641/Alr4641. (A) Northern-blotting hybridization analysis. Total RNA was isolated from Anabaena PCC7120 grown

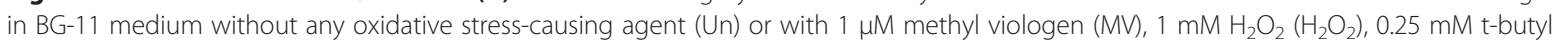
hydroperoxide (t-Bx), $50 \mathrm{mM} \mathrm{NaCl}(\mathrm{NaCl}), 100 \mathrm{mM}$ sucrose (Suc), resolved (5 $\mathrm{mg}$ per lane) on formaldehyde-agarose gels, transferred onto a nylon membrane and probed with the DIG-labeled alr4641 ORF. The 900 -nt transcript is shown by an arrow. Blot on the left panel was exposed to the X-ray film for $30 \mathrm{~s}$ whereas the one on the right was exposed for $15 \mathrm{~min}$. (B) Time course of alr4641 expression. The wild-type Anabaena PCC7120 cells were treated with $\mathrm{H}_{2} \mathrm{O}_{2}(250 \mu \mathrm{M})$ and total RNA isolated at time points indicated. Total RNA (1 $\left.\mu \mathrm{g}\right)$ from each time point was spotted on a nylon membrane and hybridized to the DIG-labeled alr4641 probe. (C) The wild-type Anabaena PCC7120 was treated with different concentrations of $\mathrm{MV}, \mathrm{H}_{2} \mathrm{O}_{2}, \mathrm{t}-\mathrm{Bx}$, cumeme hydroperoxide (Cux), $\mathrm{NaCl}$ or sucrose as indicated in the figure. Total RNA was isolated after $1 \mathrm{~h}$ of stress and was hybridized to the alr4641 probe. Un, RNA from untreated control cells (D) Induction of the Alr4641 protein in Anabaena. Total proteins (20 $\mu \mathrm{g}$ per lane) were isolated from Anabaena cells treated with sucrose (300 mM) or $\mathrm{NaCl}(150 \mathrm{mM})$ or $\mathrm{MV}(2 \mu \mathrm{M})$ and probed with the Alr4641 antiserum. The $23 \mathrm{kD}$ Alr4641 protein is shown by an arrow. (E) Total RNA isolated from untreated Anabaena cells (Un) or cells treated with 1 kGy or 3 kGy dose of gamma radiation was hybridized to the alr4641 probe. After exposure to 3 kGy dose of gamma radiation, total proteins were extracted from Anabaena cells and probed with the Alr4641 antiserum.

Interestingly, treatment with sucrose or $\mathrm{NaCl}$ also enhanced the levels of the alr4641 transcript (Figure 1A). Although, alr4641 expression was observed as early as after 30 min of exposure to $\mathrm{H}_{2} \mathrm{O}_{2}$, maximal expression occurred by $1 \mathrm{~h}$ after which it declined and disappeared at the end of $6 \mathrm{~h}$ (Figure 1B). Expression profile of the alr4641 transcript exposed to different concentrations of oxidative/osmotic stress causing agents for $1 \mathrm{~h}$ was monitored. With increasing concentrations, a concomitant rise in the level of the alr4641 transcript was observed (Figure 1C). Western blotting followed by immunodetection with the Alr4641 antiserum revealed salt, sucrose and MV to increase the content of the Alr4641 protein as compared to the untreated control cells (Figure 1D). Interestingly, the alr4641 transcript was also induced in response to ionizing $(\gamma)$ radiation, a physical agent that causes oxidative stress (Figure 1E). Post irradiation, during recovery, a clear enhancement in the content of the 2-Cys-Prx protein was observed (Figure 1E).

\section{Alr4641 promoter is expressed in the vegetative cells as} well as heterocysts

As distinct induction of alr4641 was observed in response to various abiotic stresses, it was desired to locate the alr4641 promoter and indentify the regulatory elements associated with it. Rapid amplification of cDNA ends (RACE) with the total RNA isolated from the $\mathrm{H}_{2} \mathrm{O}_{2}$ treated cells showed a distinct $\sim 200$-bp cDNA product (Figure 2A). Sequence analysis of $\sim 200$-bp product identified the start of alr4641 transcript to be 165-nt upstream of the translational start of the alr4641 ORF (Figure 2B). Bioinformatic analysis revealed the presence of a prokaryotic -10 and -35 -like promoter sequence and a putative FurA binding box within this promoter (Figure 2B). Electrophoretic mobility shift assays (EMSAs) showed the purified FurA protein from Anabaena PCC7120 to bind the FurA binding box (Additional file 1).

The alr4641 promoter and its adjacent DNA were cloned upstream of the $g f p$ reporter gene in reporter vector, pAM1956, and transferred into Anabaena PCC7120 


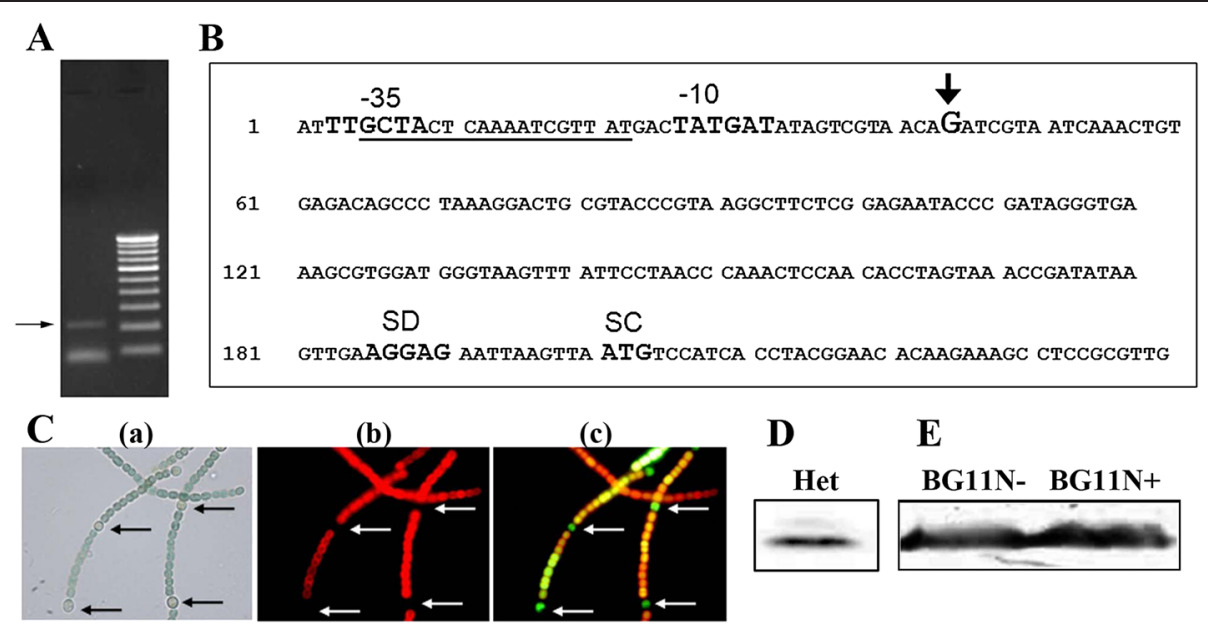

Figure 2 RACE analysis and expression of the alr4641 promoter $\left(P_{\text {alr4641 }}\right)$-gfp gene fusion. (A) RACE was performed with RNA isolated from Anabaena cells treated with $\mathrm{H}_{2} \mathrm{O}_{2}(1 \mathrm{mM})$ for $1 \mathrm{~h}$ using primers described in the Methods section. The 200-bp DNA fragment is shown by an arrow. (B) Sequence analysis of the RACE product. The transcriptional start site is indicated by +1 in the figure. The nucleotide sequence corresponding to the -10 and -35 region of the alr4641 promoter, the ribosome binding site (SD) and the translational start codon (SC) are denoted while the FurA-binding sequence is underlined. (C) Bright field and fluorescence micrographs (1500X). An4641 prom cells, were grown in medium lacking combined nitrogen for several generations and visualized under a fluorescence microscope; (a) bright field image, (b) fluorescence micrograph of cells using Hg-Arc lamp (excitation BP, 546-612 nm and emission LP, $515 \mathrm{~nm}$ ) and (c) fluorescence micrograph (excitation BP, 450-490 nm and emission LP, $515 \mathrm{~nm}$ ). Heterocysts are depicted by arrows. (D) Total protein from heterocysts $(20 \mu \mathrm{g})$ was resolved by SDS-PAGE and probed with the Alr4641 antiserum. (E) Detection of the Alr4641 protein. The wild-type Anabaena PCC7120 cells were grown in BG-11 medium without (BG11N-) or with combined nitrogen (BG11 N+). Protein extracts (60 $\mu \mathrm{g}$ per lane) were resolved by SDS-PAGE (10\% gel), and immunodetected with the Alr4641 antiserum on Western blots. The $23 \mathrm{kD}$ Alr4641 protein is depicted by an arrow.

(An4641prom). An4641prom was grown under nitrogenfixing conditions and subjected to microscopic analysis. Interestingly, along with the vegetative cells, GFP fluorescence was also observed in the heterocysts indicating that the alr4641 promoter was active in heterocysts as well as in the vegetative cells (Figure 2C). Moreover, the Alr4641 protein was also detected in proteins extracted from heterocysts on Western blots (Figure 2D). Expression of the Alr4641 protein was monitored in the wild-type Anabaena cultures grown under nitrogen-supplemented or nitrogen-fixing conditions. No significant difference in the production of Alr4641 was observed (Figure 2E) suggesting that the absence of combined nitrogen in the growth medium does not affect Alr4641 expression in Anabaena.

\section{Oligomerization of Alr4641 is independent of cysteine residues}

Enhanced production of the Alr4641 protein in response to abiotic stresses and its localization in both heterocysts as well as vegetative cells suggested that Alr4641 could be an important player in detoxification of ROS in Anabaena. Hence, we wished to characterize the biophysical and biochemical properties of the Alr4641 protein in order to gain insights into its function. Analysis with the SMART (http://smart.embl-heidelberg.de/) or BLAST revealed the protein encoded by alr4641 to be a typical 2Cys-Prx containing the conserved VCP motif. The $612 \mathrm{bp}$ long alr4641 ORF encoded a $23 \mathrm{kD}$ (203 amino acid) protein with the AhpC/TSA domain extending from the $13^{\text {th }}$ amino acid to the $146^{\text {th }}$ amino acid. Analysis of the Alr4641 protein sequence showed the presence of GGVG and YF motifs that are typical of eukaryotic 2-Cys-Prx (Figure 3A). Based on homology with other peroxiredoxins, cysteines at position 56 (Cys-56) and 178 (Cys-178) of Alr4641 were speculated to be the putative peroxidatic and resolving cysteine residues respectively (Figure 3A).

For functional characterization, the 2-Cys peroxiredoxin protein (Alr4641) from Anabaena was over-expressed in $E$. coli with N-terminal His-tag and purified near to homogeneity by affinity chromoatography (Figure 3B). The putative peroxidatic (Cys-56) and resolving (Cys-178) cysteines of Alr4641 were individually mutated to serine by sitespecific mutagenesis and the corresponding proteins (Alr4641C56S and Alr4641C178S) were purified to near homogeneity. Gel filtration analysis revealed Alr4641 to elute in a fraction corresponding to decamer/dodecamer (Figure 3C). Native PAGE analysis showed the wild-type Alr4641 as well as the mutants to be present as higher oligomers (Figure 3D). These results suggest that peroxidatic and resolving cysteine residues are not involved in oligomer formation. On SDS-PAGE, the wild-type Alr4641 protein migrated as a monomer under reducing conditions (in presence of DTT), while in absence of DTT, a $50 \mathrm{kD}$ protein, corresponding to its dimeric form was observed, indicating formation of inter subunit disulfide bond. Electrophoretic separation showed both Alr4641C56S 


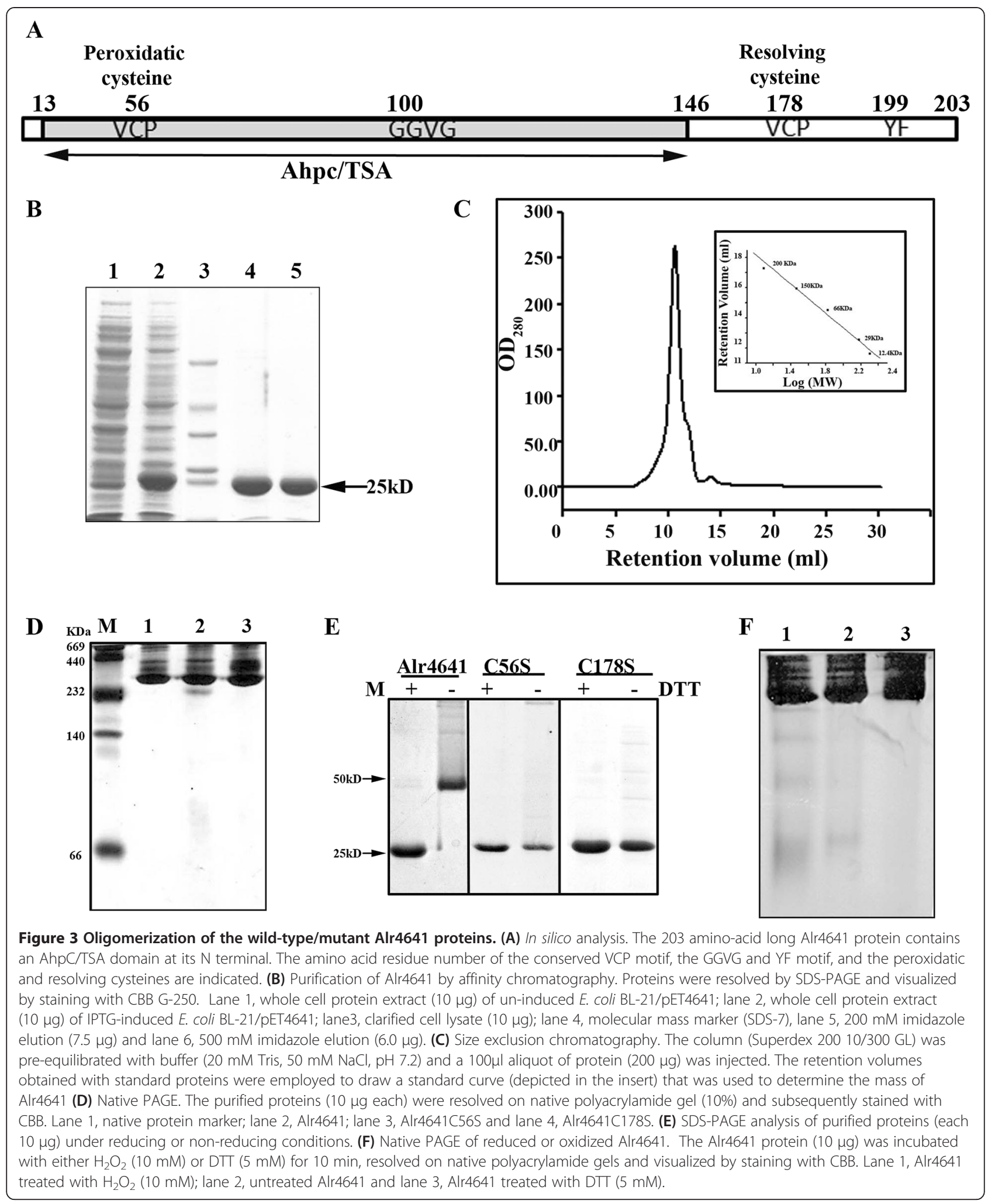

and Alr4641C178S to be present as monomers irrespective of the presence or absence of reducing agent (DTT) on SDS PAGE (Figure 3E). Tryptophan fluorescence spectra of the wild-type Alr4641, Alr4641C56S and Alr4641C178S proteins showed no shift in peak position at $340 \mathrm{~nm}$ suggesting that the absence of Cys residues does not alter the compactness of their structure (Additional file 2). Reduction of the wild-type 
Alr4641 did not alter the oligomeric state of the protein, but on treatment with $\mathrm{H}_{2} \mathrm{O}_{2}$, few smaller oligomers along with the major higher oligomeric form were observed on native PAGE (Figure 3F). As the oligomeric state of Alr4641 remained unchanged, it was of particular interest to analyze the chaperone/peroxidase function of Alr4641 after exposure to oxidizing or reducing agents. Results pertaining to these activities are described in the next two sections.

\section{Alr4641 protein loses its chaperone function on reduction} The Alr4641 protein was assessed for its capability to function as a molecular chaperone employing the malate dehydrogenase $(\mathrm{MDH})$ aggregation assay. At $55^{\circ} \mathrm{C}$, the $\mathrm{MDH}$ protein showed substantial aggregation after $10 \mathrm{~min}$ whereas the purified Alr4641 protein by itself did not form any aggregates. When purified Alr4641 was added to $\mathrm{MDH}$, a marked decrease in the scattering of light was observed indicating reduced aggregation of $\mathrm{MDH}$. Chaperone activity of Alr4641 was increased with increasing concentration of the protein (Alr4641) indicating that this protein did indeed function as a molecular chaperone (Figure 4A). Alr4641C56S and Alr4641C178S both showed chaperone activity similar to the wild-type Alr4641 (Figure 4B). Alr4641 treated with $\mathrm{H}_{2} \mathrm{O}_{2}$ retained chaperone activity, but interestingly, the Alr4641 protein on reduction with dithiothretol (DTT) failed to show this activity (Figure 4C). However, when the DTT-reduced Alr4641 was treated with $\mathrm{H}_{2} \mathrm{O}_{2}$, it regained its chaperone activity (Figure $4 \mathrm{C}$ ). $\mathrm{CD}$ spectropolarimetric analysis showed significant differences in the secondary structure of the reduced and the non-reduced wild-type Alr4641 suggesting that the oxidized and reduced forms were inherently different from each other (Figure 4D).

\section{Alr4641 protects plasmid DNA from oxidative damage and shows Trx/NTRC-dependent peroxidase activity}

Metal catalyzed oxidation (MCO) was performed to verify if the purified Alr4641 protein could function as an antioxidant protein. The plasmid DNA was completely degraded when subjected to MCO assay in the absence of Alr4641. However, addition of the Alr4641 protein
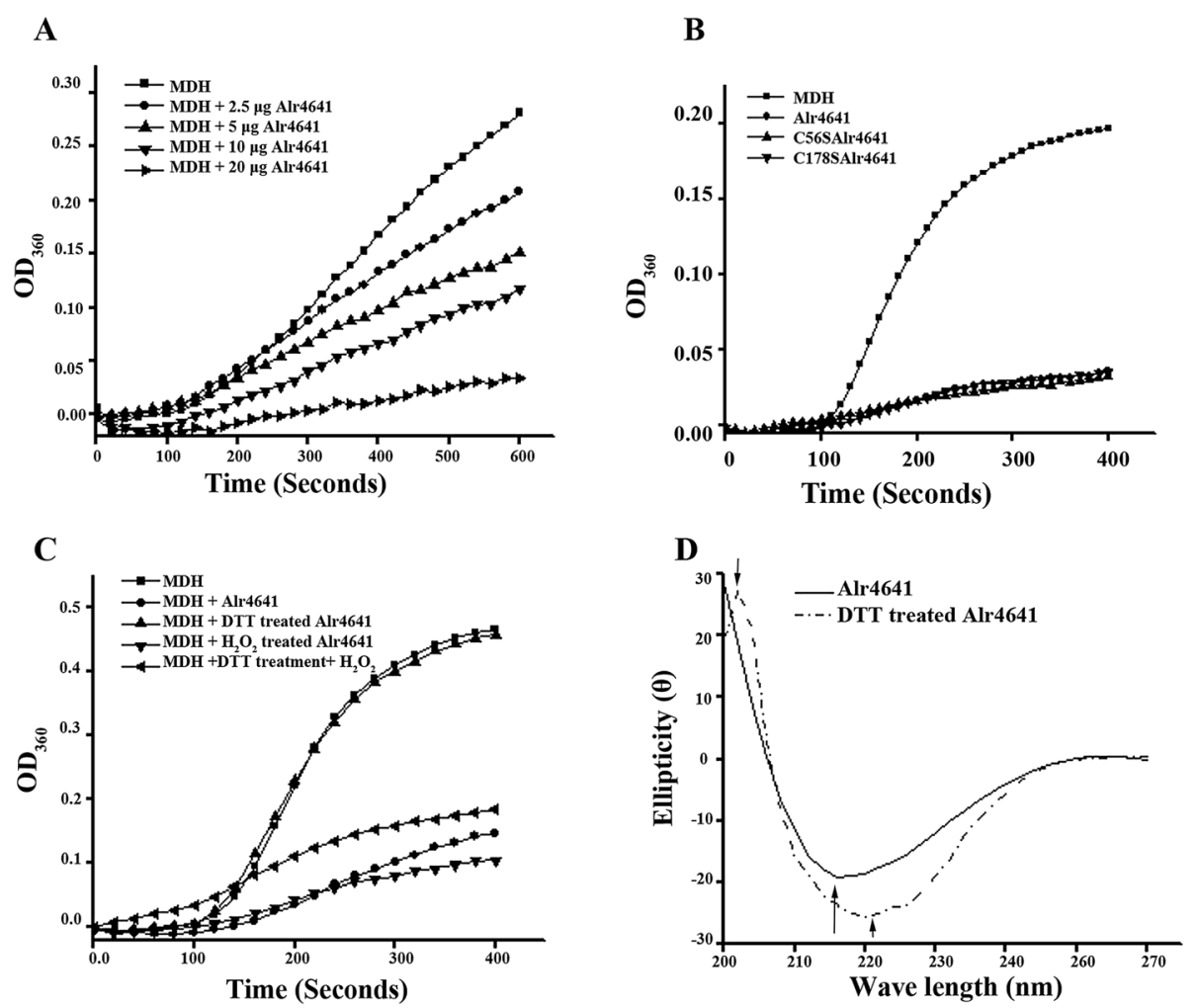

Figure 4 Alr4641 functions as a molecular chaperone. (A) Chaperone activity. Light scattering due to thermal aggregation of malate dehydrogenase $(\mathrm{MDH}, 5 \mu \mathrm{M})$ in the presence of different concentrations of Alr4641 (as indicated in the figure) was monitored with a spectrophotometer at $360 \mathrm{~nm}$. (B) Light scattering of MDH was monitored (as described in A) in the presence of Alr4641C56S or Alr4641C178S or Alr4641 (20 $\mu \mathrm{g}$ each). (C) Chaperone activity of oxidized or reduced Alr4641. The purified Alr4641 protein was treated with $\mathrm{H}_{2} \mathrm{O}_{2}(10 \mathrm{mM})$ or DTT (10 mM) for 60 min and tested for chaperone activity with $\mathrm{MDH}(5 \mu \mathrm{M})$. In another reaction, the DTT-treated Alr4641 was incubated with $\mathrm{H}_{2} \mathrm{O}_{2}(5 \mathrm{mM})$ for 30 min and then employed for the chaperone assay. (D) Secondary structure analysis. The purified Alr4641 protein treated with DTT (10 mM) for 30 min or the control Alr4641 protein i.e. without DTT treatment (as indicated in the figure), was analyzed in a CD spectropolarimeter. 
protected the plasmid DNA from degradation (Figure 5A). The ability of Alr4641 to scavenge hydrogen peroxide with different electron donor systems [DTT, reduced glutathione (GSH) or thioredoxin A (TrxA)] was evaluated. The Alr4641 protein could use TrxA and DTT but not $\mathrm{GSH}$ to detoxify $\mathrm{H}_{2} \mathrm{O}_{2}$ (Figure $5 \mathrm{~B}$ ). The purified Alr4641 protein showed TrxA-dependent activity whereas both Alr4641C56S and Alr4641C178S failed to do so (Figure 5C).

The NTRC protein from Anabaena was over-expressed in $E$. coli, purified by affinity chromatography (Figure 5D). Surface Plasmon Resonance (SPR) was employed to study interaction of Alr4641 with NTRC. The Alr4641 protein was immobilized on a bare gold sensor chip while NTRC was used in the mobile phase. The interaction between the two proteins was confirmed by a concentrationdependent increase in the SPR signal (Figure 5E). Equilibrium analysis showed a good Lorentz fit with the experimental values (Additional file 3 ) and the equilibrium constant $\left(\mathrm{K}_{\mathrm{D}}\right)$ was observed to be $1.037 \times 10^{-6} \pm$ $4.76 \times 10^{-8}$ M. NTRC was also employed to evaluate the peroxidase activity of Alr4641 in the presence of different peroxidase substrates. Among the three substrates tested, best activity was observed with $\mathrm{H}_{2} \mathrm{O}_{2}$ followed by t-butyl

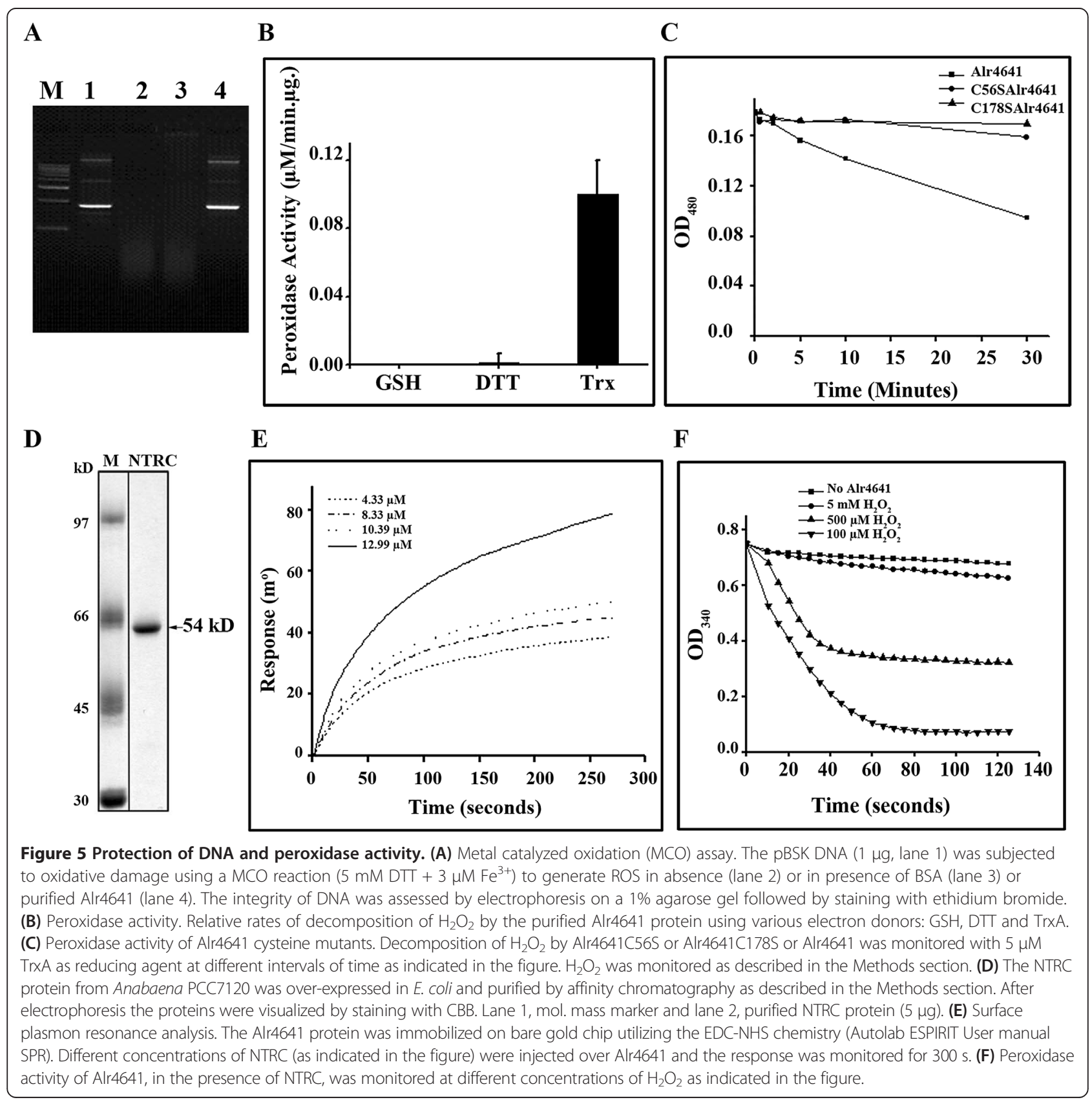


hydroperoxide and cumeme hydroperoxide (Additional file 4). With increasing concentrations of $\mathrm{H}_{2} \mathrm{O}_{2}$, a reduction in the peroxidase activity was observed, indicating that excess $\mathrm{H}_{2} \mathrm{O}_{2}$ inactivated the Alr4641 protein (Figure 5F).

\section{Alr4641 forms over-oxidized monomer in vivo under conditions of oxidative stress}

The peroxidatic cysteine of 2-Cys-Prxs, on treatment with excess of oxidizing agents (e. g. $\mathrm{H}_{2} \mathrm{O}_{2}$ ), becomes overoxidized and is unable to form disulphide bridges. Hence, the over-oxidized 2-Cys-Prx shows up as a monomer on non-reducing SDS-polyacrylamide gels [10]. To analyze the formation of over-oxidized monomers in vivo in Anabaena during oxidative stress, cells were treated with different oxidizing agents and analyzed (Figure 6). Treatment with $\mathrm{H}_{2} \mathrm{O}_{2}$ but not methyl viologen produced detectable Alr4641 monomers, whereas at the concentration of t-butyl hydroperoxide ( $t$ - $\mathrm{Bx}$ ) employed, partial overoxidation of Alr4641 occurred and both monomeric as well as dimeric forms of the protein were observed (Figure 6A). Exposure of Anabaena to $6 \mathrm{kGy}$ dose of gamma radiation also resulted in the formation of the Alr4641 monomers (Figure 6B). However, the overoxidized form disappeared during recovery and $24 \mathrm{~h}$ after irradiation, only the dimeric form of Alr4641 was observed (Figure 6C).

\section{Over-expression of Alr4641, but not Alr4641C56S, causes reduction in intracellular $\mathrm{ROS}$ generation on exposure to $\mathrm{H}_{2} \mathrm{O}_{2}$}

To assess the in vivo role of catalytic cysteine (C56), the wild-type alr4641 or alr4641C56S were individually cloned between the strong light inducible $p s b A$ promoter $\left(\mathrm{P}_{p s b A}\right)$ and the $g f p$ (green fluorescent protein) gene in pAM1956 (denoted as pAM4641 and pAM4641C56S respectively). Both these constructs were separately transferred to Anabaena PCC7120. Under fluorescence microscope, the filaments of An4641 (Anabaena expressing Alr4641) and $\mathrm{AnC}_{56 \mathrm{~S}}{ }^{+}$(Anabaena over-expressing Alr4641C56S) appeared green indicating the presence of pAM4641 or pAM4641C56S (Figure 7A, B). When probed with the antiAlr4641 antiserum, abundant production of the Alr4641 or Alr4641C56S protein was observed in the cell-free extract of $\mathrm{An}_{4641^{+}}$or AnC56S ${ }^{+}$respectively (Figure 7C). When analyzed on non-reducing SDS-PAGE, the wild-type Alr4641 was mostly present in its dimeric form whereas Alr4641C56S remained largely monomeric (Figure 7D). Native PAGE followed by Western blot analysis with cell free extracts of An4641 ${ }^{+} / \mathrm{AnC} 56 \mathrm{~S}^{+}$revealed the occurrence of higher oligomeric form in vivo in both the cases (Figure 7E) as also observed with the purified proteins (Figure 3D).

Earlier, the NTRC protein was shown to physically interact with the purified Alr4641 protein (Figure 5E). In

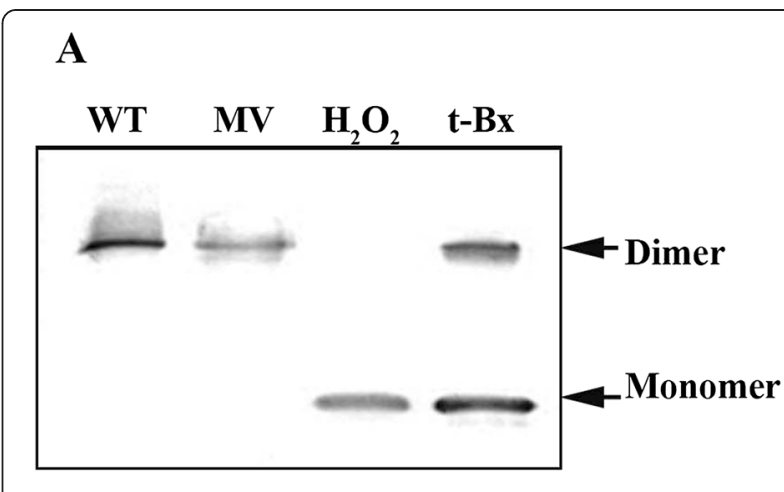

B

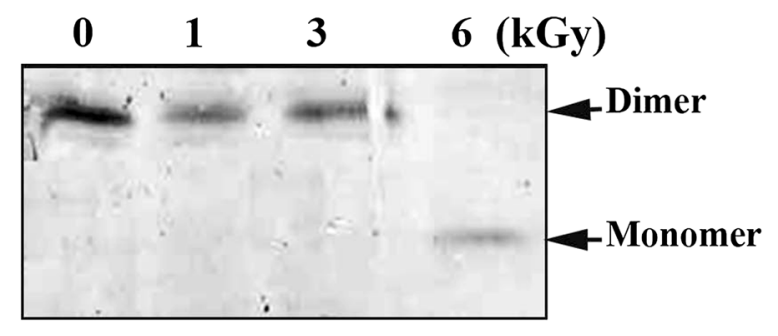

C 1h $\quad 4 h \quad 16 h$

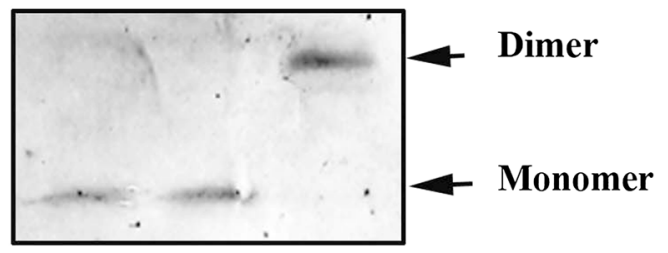

Figure 6 Over-oxidation of the Alr4641 protein in Anabaena PCC7120. (A) Treatment with oxidative stress-inducing agents. Exponential phase cultures of Anabaena PCC7120 (3.0 $\mu \mathrm{g}$ chlorophyll $\mathrm{a} \mathrm{ml}^{-1}$ ) were exposed to methyl viologen, (MV), hydrogen peroxide, $\left(\mathrm{H}_{2} \mathrm{O}_{2}\right)$ or t-butyl hydroperoxide, (t-Bx) for $30 \mathrm{~min}$. Cell free extracts ( $25 \mu \mathrm{g}$ protein per lane) were resolved on non-reducing SDSpolyacrylamide gel, electroblotted onto a nitrocellulose membrane and probed with the Alr4641 antiserum. The dimeric (non-overoxidized) form and the monomeric (oxidized) form are indicated in the figure. (B) Over-oxidation of Alr4641 in response to gamma ( $\mathrm{Y}$ ) radiation. Exponential phase cultures of Anabaena PCC7120 $(6.0 \mu \mathrm{g}$ chlorophyll a ml${ }^{-1}$ ) were exposed to different doses of $\mathrm{Y}$-radiation as indicated in the figure. The Alr4641 protein was detected immediately after irradiation as described in A. (C) After exposure to 6 kGy dose of $\mathrm{Y}$-radiation, Anabaena cells were incubated in $\mathrm{BG} 11 \mathrm{~N}+$ medium for recovery from radiation stress. Cells were removed at time points indicated and the Alr4641 protein was detected as before.

addition, capability of NTRC to associate with the Alr4641 protein from An $4641^{+}$cells free extracts was assessed by pull down experiments. As shown in Figure 7F, substantial amount of Alr4641 was bound when NTRC was immobilized on NiNTA agarose. In the absence of NTRC, hardly any Alr4641 bound to the empty resin (Figure 7F). 


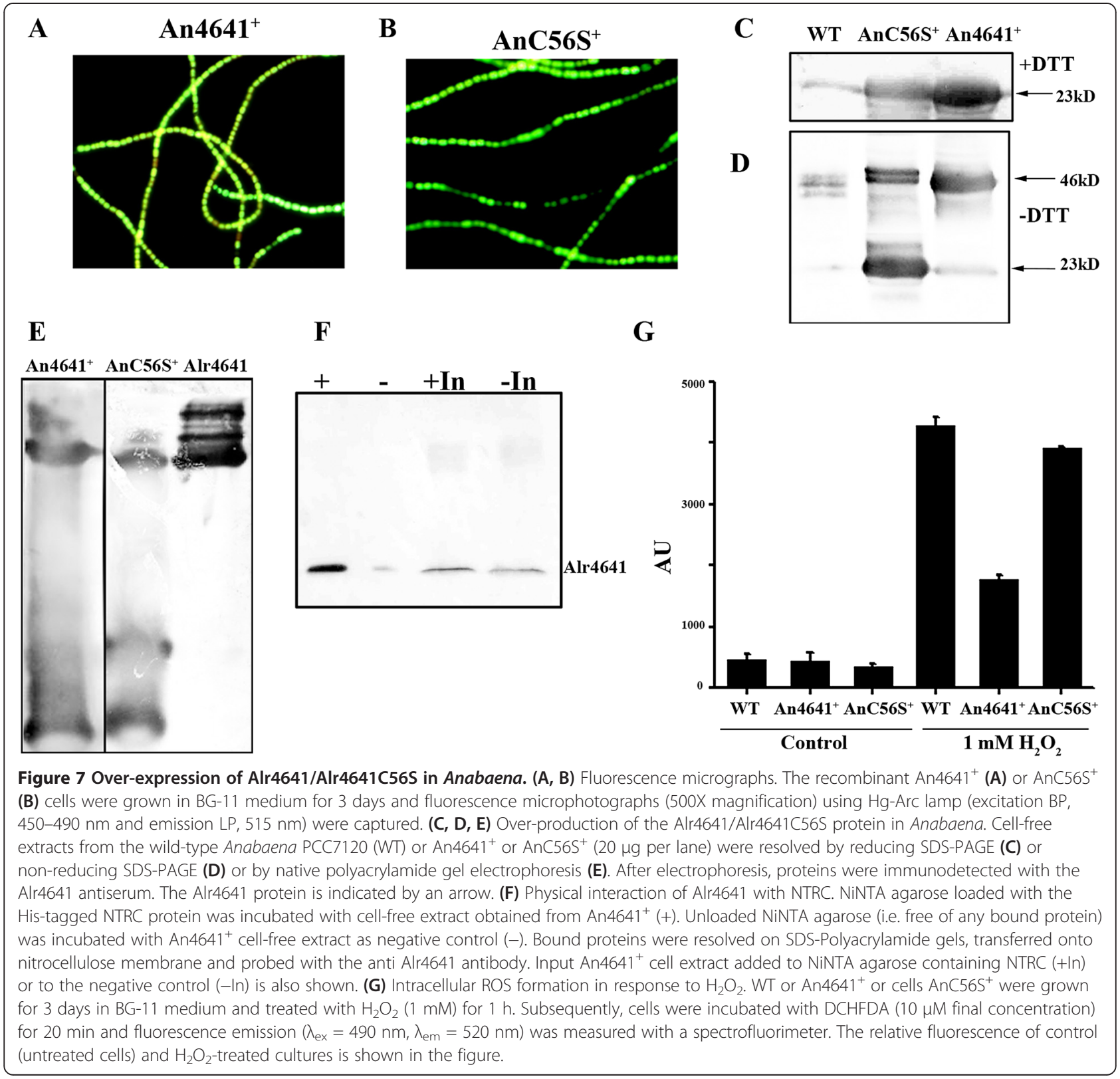

The intracellular levels of ROS in the wild-type Anabaena, An $4641^{+}$or AnC56S ${ }^{+}$cells exposed to $\mathrm{H}_{2} \mathrm{O}_{2}$ for $1 \mathrm{~h}$ were assessed with the fluorogenic probe DCHFDA. Under control conditions, ROS levels were very low in all types of cells. However, on exposure to $1 \mathrm{mM} \mathrm{H}_{2} \mathrm{O}_{2}$, substantially higher levels of ROS were observed in the wild-type Anabaena PCC7120 and AnC56S ${ }^{+}$cells as compared to the An $4641^{+}$cells (Figure 7G).

\section{Over-production of Alr4641 protects the photosynthetic} machinery and enhances survival in response to oxidative stress in Anabaena

Treatment with $1 \mathrm{mM} \mathrm{H}_{2} \mathrm{O}_{2}$ for $24 \mathrm{~h}$ resulted in pronounced bleaching caused by a sharp reduction in the chlorophyll $a$ content in the wild-type Anabaena PCC7120 but not in $\mathrm{An}_{4641^{+}}$cells (Figure 8A and B). A substantial decline was observed in $\mathrm{F}_{\mathrm{v}} / \mathrm{F}_{\mathrm{m}}$ of $\mathrm{H}_{2} \mathrm{O}_{2}$-stressed wild-type Anabaena cells, while An $4641^{+}$showed $\mathrm{F}_{\mathrm{v}} / \mathrm{F}_{\mathrm{m}}$ comparable to the unstressed control cells (Table 1). Light curves (LC) of electron transport rate (ETR) with the wild-type Anabaena or An $4641^{+}$were carried out to analyze electron transport rate in PSII in response to $\mathrm{H}_{2} \mathrm{O}_{2}$. The ETR (II) of An $4641^{+}$on treatment with $\mathrm{H}_{2} \mathrm{O}_{2}$ was similar to that of control cells. In contrast, a severe decrease in ETR (II) was observed when the wild-type Anabaena was treated with $\mathrm{H}_{2} \mathrm{O}_{2}$ (Figure $8 \mathrm{C}$ ). Rate of $\mathrm{CO}_{2}$ fixation decreased marginally in the An4641 ${ }^{+}$treated with $\mathrm{H}_{2} \mathrm{O}_{2}$ as compared to a 20 -fold reduction observed in the similarly treated wild- 


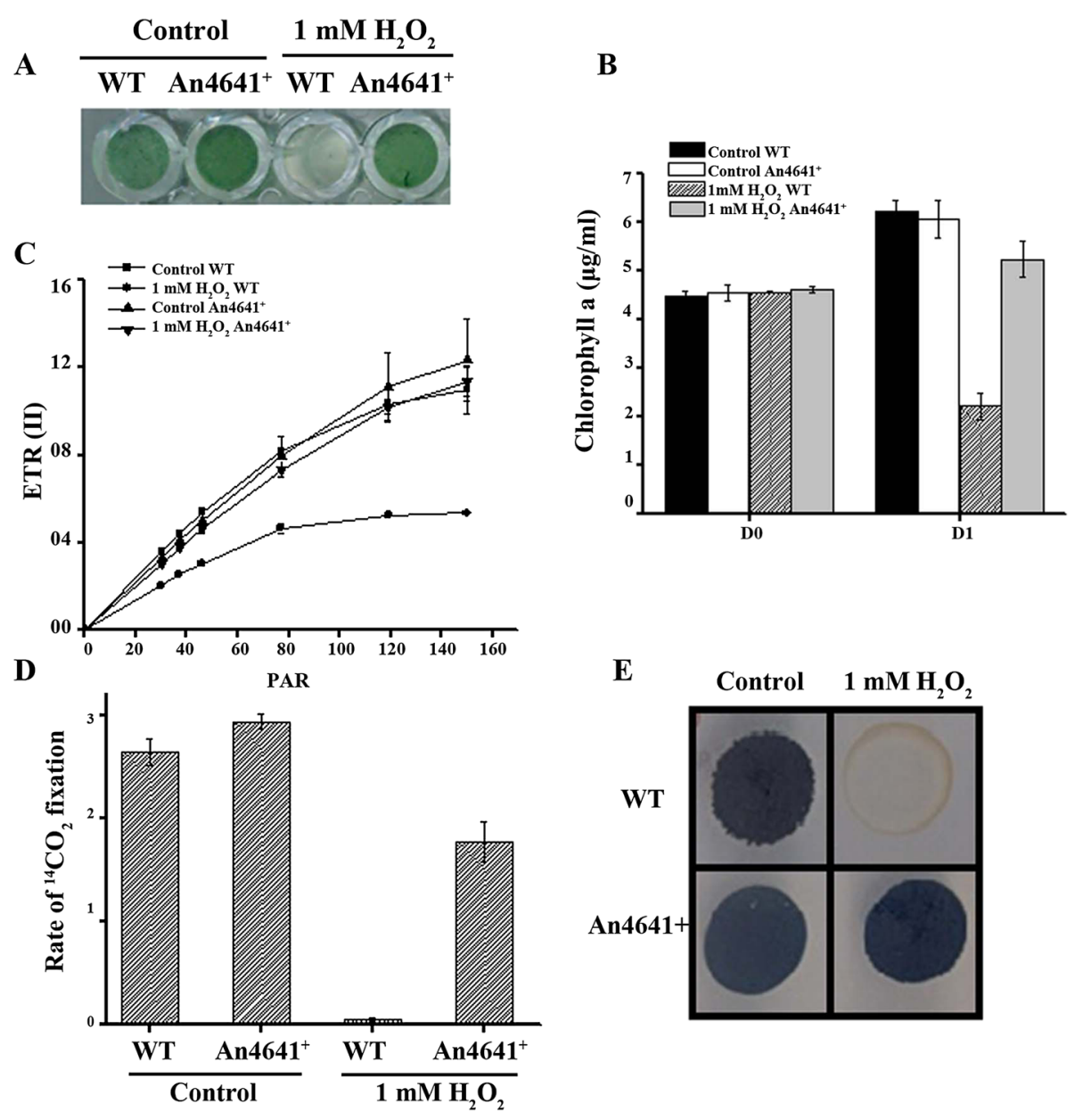

Figure 8 Oxidative stress tolerance of the wild-type Anabaena PCC7120 (WT) and An4641 ${ }^{+}$. (A) Three-day-old Anabaena cultures were inoculated in a fresh growth medium and subjected to $\mathrm{H}_{2} \mathrm{O}_{2}(1 \mathrm{mM})$ stress for 2 days. Later, cultures were transferred onto a microtitre plates and photographed. (B) The chlorophyll a content of cultures shown in (A) was determined immediately (day 0) or after two days of exposure to $\mathrm{H}_{2} \mathrm{O}_{2}$. (C) Rapid light curves of ETR (II). Data were collected through the light response reaction from untreated (control cells) or cells treated with $\mathrm{H}_{2} \mathrm{O}_{2}(1 \mathrm{mM})$ as indicated in the figure. (D) The rate of ${ }^{14} \mathrm{CO}_{2}$ fixation [ $\mu$ moles of $\mathrm{CO}_{2}$ fixed ( $\mu \mathrm{g}$ chlorophyll a $)^{-1} \mathrm{~h}^{-1}$ ] of the wild-type Anabaena PCC7120 (WT) or An4641 $1^{+}$cells after treatment with $1 \mathrm{mM} \mathrm{H}_{2} \mathrm{O}_{2}$ for $24 \mathrm{~h}$. (E) The wild-type Anabaena PCC7120 (WT) or An4641 ${ }^{+}$cells after treatment with $\mathrm{H}_{2} \mathrm{O}_{2}(1 \mathrm{mM})$ for 2 days were spotted (100 $\mu$ leach) on BG-11 agar plate. The plates were incubated under continuous illumination and photographed after 14 days of incubation.

type Anabaena PCC7120 (Figure 8D). The wild-type Anabaena PCC7120 treated with $\mathrm{H}_{2} \mathrm{O}_{2}$ failed to grow on BG-11 plates indicating loss in viability. On the other hand, similarly treated An $4641^{+}$grew on plates like the unstressed control cells (Figure 8E).

Table 1 PSII activity in Anabaena cultures treated with $\mathrm{H}_{2} \mathrm{O}_{2}$

\begin{tabular}{|c|c|}
\hline Strain (treatment) & $F_{v} / F_{m}$ \\
\hline WT (control) & $0.287333 \pm 0.00585$ \\
\hline WT $\left(\mathrm{H}_{2} \mathrm{O}_{2}\right)$ & $0.195 \pm 0$ \\
\hline An4641 (control) & $0.286 \pm 0.018358$ \\
\hline $\operatorname{An} 4641^{+}\left(\mathrm{H}_{2} \mathrm{O}_{2}\right)$ & $0.28275 \pm 0.01345$ \\
\hline
\end{tabular}

\section{Discussion}

Prxs form a phylogenetically ancient group of enzymes with a major role in detoxification of peroxides [2]. Generally, Prxs show a moderate catalytic activity, but their high cellular content seems to compensate for their reduced efficiency in decomposing peroxides [33]. It is believed that the antioxidant system in chloroplasts, organelle with highest content of Prxs in a plant cell, has evolved from cyanobacteria. Anabaena bears a resemblance to plant chloroplasts in being equipped with an oxidation sensitive 2-Cys-Prx (i.e. Alr4641) along with its reducing partner NTRC [32] and showing a low catalase activity $[8,25]$.

The presence of the 0.9-knt alr4641 transcript (Figure 1) indicates that in spite of their adjacent location, the 
alr4642 ORF (642-bp, located 191-bp downstream of alr4641) and alr4641 are not co-transcribed, signifying that alr4641 forms a monocistronic operon. The promoter sequence found immediately upstream of this start site showed the presence of FurA (a transcriptional repressor) binding site (Figure 2) and the purified FurA protein from Anabaena bound the DNA fragment containing this sequence (Additional file 1). Gonzalez et al. have shown production of the Alr4641 protein to be reduced in the FurA-overexpressing Anabaena PCC7120. All these results imply that FurA regulates transcription of alr4641 in Anabaena [34].

In response to different abiotic stresses, the 2-Cys-prx gene transcript was enhanced in Synechococcus PCC7942 but not Synechocystis PCC6803 suggesting that transcriptional induction of 2-Cys-prx differs among cyanobacteria [35]. In Anabaena, along with methyl viologen and $\mathrm{H}_{2} \mathrm{O}_{2}$, gamma radiation (a physical agent that causes oxidative stress) could also enhance production of the alr4641 transcript or the Alr4641 protein (Figure 1) [27]. Interestingly, salinity as well as osmotic stress also increased production of the Alr4641 protein (Figure 1), indicating that Alr4641 may be a multiple stress induced protein. This is not unusual as several environmental stresses (salinity, drought, heavy metals, heat shock etc.) generate ROS [12], which in turn may ultimately enhance production of the Alr4641 protein.

Employing pull down assay and SPR analysis, NTRC was shown to physically interact with Alr4641 (Figures 5E, $7 F)$ suggesting that NTRC is likely to be the physiological reductant of Alr4641 in Anabaena. In vivo, on treatment with $\mathrm{H}_{2} \mathrm{O}_{2}$, the recombinant AnC56S ${ }^{+}$strain (that overexpresses Alr4641C56S) showed higher ROS levels compared to the An4641 ${ }^{+}$strain (that over-expresses the wild-type Alr4641) (Figure 7G). This underscores the importance of peroxidatic cysteine of Alr4641 for detoxification of $\mathrm{H}_{2} \mathrm{O}_{2}$ in vivo in Anabaena.

In general, the purified 2-Cys-Prx isolated from different organisms co-exists in various forms i.e. dimeric, decameric and high molecular wt. complexes [36]. In contrast, in its native form, Alr4641 as well as its cysteine mutants appeared as decamers in vitro, (Figure 3) or in vivo (Figure 7E). Moreover, irrespective of the redox state (i.e. whether oxidized or reduced), Alr4641 appeared as decamer (Figure 3) indicating that the disulfide bonds are not involved in oligomerization.

Generally, along with conformational change, the oligomeric state of 2-Cys Prx has also been linked to its dynamic redox state, which in turn determines its function [36]. Chaperone activity of 2-Cys-Prx has been generally linked to their oligomerization state [20]. The higher molecular weight complex shows chaperone function, the dimeric form mostly functions as a peroxidase, whereas the decameric form shows both these activities [37]. Although, reduction of Alr4641 with DTT did not change its oligomeric nature, its chaperone activity was severely reduced (Figure 4). Loss of chaperone function was observed on reducing Alr4641C56S and Alr4641C178S too (data not shown), suggesting that reduction in chaperone activity was not due to disruption of disulphide bonds. In contrast, treatment with $\mathrm{H}_{2} \mathrm{O}_{2}$ did not affect the chaperone activity of Alr4641, whereas a substantial loss in peroxidase activity was observed (Figure 5F). Apparently, chaperone/ peroxidase activity of Alr4641 does not depend on its oligomeric status, but is decided by the redox state of the protein i.e. the reduced form is more likely to function as a peroxidase while the oxidized form is more liable to function as a chaperone. A model depicting the above phenomena is described in the Figure 9. Although, thought to be a specific disulphide bond reducing agent, DTT is known to affect function of proteins not containing any cysteine residues [38], and it is proposed that DTT may act as a general reducing agent that causes changes in the global structure of proteins [39]. Reduction of 2-Cys-Prx from Arabidopsis with DTT also resulted in altered secondary structure [37]. In this study too, a distinct difference in the $\mathrm{CD}$ spectra of reduced and non-reduced Alr4641 was observed (Figure 4), indicating that treatment with DTT causes a change in the secondary structure.

Excess $\mathrm{H}_{2} \mathrm{O}_{2}$ over-oxidizes the peroxidatic cysteine, rendering Alr4641 incapable of peroxidase activity [8]. Interestingly, high dose of $\gamma$-radiation could also over-oxidize the 2-Cys-Prx (Figure 6B) preventing the formation of disulfide bond. Post irradiation, on SDS PAGE, the monomeric form of Alr4641 disappeared and only the dimeric form could be seen after $24 \mathrm{~h}$, indicating the reversion of the over-oxidised Alr4641protein to its normal form (Figure 6C). It is suggested that the recovery of the overoxidized Alr4641 is facilitated by the sulfiredoxin (Srx) protein, which reverses the over-oxidation in vivo [40].

In Anabaena, depletion of combined nitrogen from medium leads to formation of heterocysts, the specialized cells that fix nitrogen [41]. It should be noted that in spite of lowered $\mathrm{O}_{2}$ content, ROS are generated by photosystem I (PSI) and respiratory electron transport in heterocysts [42]. Also, when the ratio of nitrogenase reductase to $\mathrm{O}_{2}$ is greater than 4 , nitrogenase reductase reduces oxygen to $\mathrm{H}_{2} \mathrm{O}_{2}$ without being inactivated by oxygen [43]. Thus the $\mathrm{H}_{2} \mathrm{O}_{2}$ produced in heterocysts has to be removed promptly. Prxs are known to be differentially distributed among the vegetative cells and heterocysts [29] and among the four PrxQ-like proteins (Alr3183, Alr2503, Alr2375 and Alr2556) from Anabaena, only Alr2375 was detected in heterocysts [44]. In our study, promoter activity ( $P_{\text {alr } 4641^{-} \text {-GFP fluorescence) }}$ as well the Alr4641 protein was observed in heterocysts as well as vegetative cells (Figure 2), indicating that it 


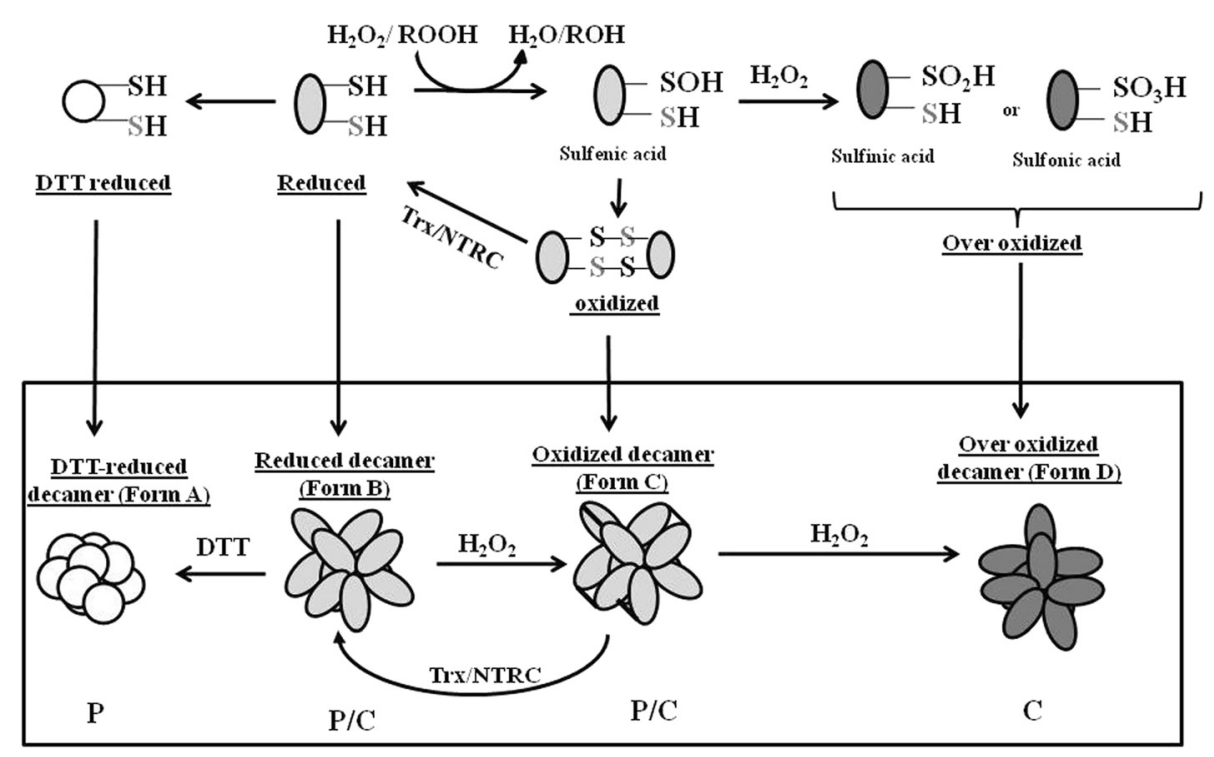

Figure 9 A model depicting redox-dependent functional switching of Alr4641. Rectangular box in the lower panel represents the oligomeric (decameric) structure of Alr4641 while the upper panel shows the state of catalytic cysteine residues of the individual monomeric units. Various conformational forms of the Alr4641 protein i.e. DTT-reduced decamer (Form-A), reduced decamer (Form-B), oxidized decamer (Form-C) and over-oxidized decamer (Form-D) are shown in the figure. Alr4641 exists as decamer irrespective of its redox state or disulphide linkage status) in all the above-mentioned conformations. Monomeric units corresponding to various forms are depicted as follows: Form- $A$, white circle; Form-B and Form-C, light-grey oval and Form-D, dark-gray oval. Form-B (with free thiol groups) on oxidation with $\mathrm{H}_{2} \mathrm{O}_{2}$ forms inter-molecular disulfide bonds (indicated with black lines in the lower panel), resulting in the formation of oxidized decamer (i.e. Form-C). Form-B is regenerated from Form- $C$ by electron donors like Trx and NTRC. However, with excess $\mathrm{H}_{2} \mathrm{O}_{2}$, the cysteinyl residue of the peroxidatic cysteine of Form-B is over-oxidised to sulfinic/sulfonic acid (Form-D). Reduction of Alr4641 with DTT not only results in the loss of disulfide bonds but also changes the overall structure of the protein (Form-A). Form-B, Form- $C$ and Form-D show chaperone activity (indicated by " $\mathrm{C}$ "), but fails to show this activity. On the other hand, Form-A, Form-B and Form- $C$ function as peroxidase (indicated by "P"), whereas the over-oxidized Alr4641 i.e. Form- $D$ is unable to do so. To summarize, under reducing conditions, Alr4641 is more likely to function as a peroxidase, whereas under oxidizing surroundings, it is more likely to work as a chaperone.

may play a role in detoxifying peroxides in vegetative cells and heterocysts.

Hydrogen peroxide $\left(\mathrm{H}_{2} \mathrm{O}_{2}\right)$ is a commonly occurring reactive oxygen species (ROS) in biological systems and cyanobacteria have been shown to be generally more sensitive to $\mathrm{H}_{2} \mathrm{O}_{2}$ than other phototrophs [45]. As Anabaena PCC7120 does not show good catalase activity $[8,27]$, it is suggested that Prxs may be the principal components that detoxify $\mathrm{H}_{2} \mathrm{O}_{2}$ in this organism. $\mathrm{H}_{2} \mathrm{O}_{2}$ damages photosynthetic apparatus and severely affects $\mathrm{F}_{\mathrm{v}} / \mathrm{F}_{\mathrm{m}}$ in several cyanobacteria [46]. In the cyanobacterium Microcystis aeruginosa, treatment with $\mathrm{H}_{2} \mathrm{O}_{2}$ enhanced reactive oxygen species (ROS) accumulation, which caused destruction of pigment synthesis and led to cell death [47]. Treatment of the wild-type Anabaena PCC7120 with $\mathrm{H}_{2} \mathrm{O}_{2}$ caused (a) enhanced levels of ROS (b) decrease in photosynthetic activities and (c) loss in viability (Figure 8). However, all the above-mentioned deleterious effects were alleviated in An $4641^{+}$strain, indicating that Alr4641 can protect Anabaena from oxidative stress.

\section{Conclusions}

The present study has identified Alr4641 as an abiotic stress induced protein that plays an important role in protecting Anabaena from oxidative stress. The Alr4641 protein was found to be unique from the other reported 2-Cys-Prxs i.e. the redox state and not its oligomerization status dictated the functional switch between the peroxidase or chaperone activity of this protein. Key attributes of Alr4641 like dual function, inherent transcriptional/translational induction under different stresses, localization in both vegetative cells and heterocysts, ability to use various reducing agents for detoxifying peroxides, reflect the versatile role played by the protein in Anabaena. The recombinant Anabaena strain over expressing Alr4641 exhibited higher tolerance to oxidative stress, thus establishing its potential to serve as stress-tolerant biofertilizers in paddy fields.

\section{Methods}

Organism and growth conditions

Anabaena PCC7120 cultures were grown in BG-11 liquid medium, pH 7.0 with combined nitrogen $\left(17 \mathrm{mM} \mathrm{NaNO}_{3}\right)$ 
under continuous illumination $\left(30 \mu \mathrm{E} \mathrm{m} \mathrm{m}^{-2} \mathrm{~s}^{-1}\right)$, with shaking (100 rpm) or without shaking (as still culture) at $27^{\circ} \mathrm{C} \pm 2{ }^{\circ} \mathrm{C}$. Growth was assessed by monitoring the content of chlorophyll $a \mathrm{~mL}^{-1}$ of culture volume [48]. $E$. coli cells were grown in Luria-Bertani (LB) medium in the presence of appropriate antibiotics at $37^{\circ} \mathrm{C}$ with shaking at $150 \mathrm{rpm}$. The antibiotics used were $10 \mu \mathrm{g}$ neomycin $\mathrm{mL}^{-1}\left(\mathrm{Nm}_{10}\right)$ in BG-11 liquid media and $25 \mu \mathrm{g}$ neomycin $\mathrm{mL}^{-1}\left(\mathrm{Nm}_{25}\right)$ in BG-11 agar plates for recombinant Anabaena PCC 7120; and $34 \mu \mathrm{g}$ chloramphenicol $\mathrm{mL}^{-1}$ $\left(\mathrm{Cm}_{34}\right), 50 \mu \mathrm{g}$ kanamycin $\mathrm{mL}^{-1}\left(\mathrm{Kan}_{50}\right)$ or $100 \mu \mathrm{g}$ carbenicillin $\mathrm{mL}^{-1}\left(\mathrm{Cb}_{100}\right)$ for E. coli. The E. coli and Anabaena strains and plasmids used in the study are indicated in Additional file 5 .

\section{Cloning of alr4641, alr4641C56S alr4641C178S, furA and ntrc into $\mathrm{pET} 16 \mathrm{~b}$}

The alr4641 ORF was PCR amplified using genespecific primers, alr4641fwd and alr4641rev, from Anabaena PCC7120 chromosomal DNA (Additional file 6). The PCR product (612-bp) obtained was digested with NdeI and BamHI and cloned into similarly digested pET16b (Additional file 5) to obtain plasmid pET4641. The pET4641 insert was sequenced to confirm the nucleotide sequence integrity of the cloned gene. A point mutation, leading to substitution of the Cys codon at positions 56 or 178 to Ser codon was introduced into the alr4641 ORF by PCR directed site-specific mutagenesis using overlapping PCR as described earlier [25]. The PCR products (alr4641C56S and alr4641C178) containing the desired mutation were cloned into pET16b vector between the NdeI and BamHI restriction enzyme sites for over-expression in E. coli and named pET4641C56S and pET4641C178S respectively. The furA (all1691) or the ntrc (all0737) ORF was amplified with specific primers (described in Additional file 6) employing Anabaena PCC7120 genomic DNA as template. Restriction enzyme sites for $\mathrm{NcoI}$ and $\mathrm{BamHI}$ were incorporated in the forward and the reverse primers respectively. The reverse primer also had six His codons (shown in bold) followed by a stop codon. PCR product was purified, digested, and ligated to the NcoI-BamHI digested pET16b vector to give rise to $\mathrm{PETFurA}$ and $\mathrm{pETNTRC}$ respectively. All the resultant clones were confirmed by DNA sequencing.

Over-production and purification of recombinant proteins Over-production of the His-tagged Alr4641, Alr4641C56S, Alr4641C178S, FurA and NTRC proteins in E. coli BL21pLysS and their subsequent purification was performed by affinity chromatography using Ni-NTA matrix as described earlier [49]. The purified Alr4641 protein was also used to immunize rabbits for generating specific antiserum. The primary and booster immunizations and collection of the antiserum were performed at a commercial facility (Merck, India).

\section{Size exclusion chromatography (SEC)}

HPLC (AKTApure, USA) was performed using Superdex 200 10/300 GL column equilibrated at a flow rate of $0.5 \mathrm{ml} \mathrm{min}^{-1}$ at $25^{\circ} \mathrm{C}$ in Tris-buffer ( $\left.20 \mathrm{mM}, \mathrm{pH} 7.2\right)$ containing $\mathrm{NaCl}(50 \mathrm{mM})$.

\section{Chaperone activity}

The chaperone activity of purified proteins was measured by using $1 \mu \mathrm{M}$ malate dehydrogenase (MDH) as substrate in $50 \mathrm{mM}$ HEPES-NaOH $(\mathrm{pH} 8.0)$ buffer at $55^{\circ} \mathrm{C}$ with various $\operatorname{Prx}$ concentrations (4:1, 2:1, 1:1, 1:2 MDH:Prx molar ratio). Turbidity $\left(\mathrm{A}_{360}\right)$ due to substrate aggregation at $55^{\circ} \mathrm{C}$ was monitored in a spectrophotometer (JASCO, Japan) equipped with a thermostatic cell holder. When desired, the purified Alr4641/Alr4641C56S/Alr4641C178S proteins were individually treated with DTT $(5 \mathrm{mM})$ or $\mathrm{H}_{2} \mathrm{O}_{2}(10 \mathrm{mM})$ for $10 \mathrm{~min}$, passed through a desalting column and employed for the chaperone assay as described above. Assays were performed at least 4 times and representative curves are shown in the figure.

\section{Peroxidase activity assay}

For DTT dependent peroxidase assay, reaction mixture $(1 \mathrm{ml})$ containing HEPES-NaOH $(50 \mathrm{mM}, \mathrm{pH} 7.0)$ and desired concentrations of Prx proteins were pre-incubated with DTT $(3 \mathrm{mM})$ for $10 \mathrm{~min}$ at $37^{\circ} \mathrm{C}$, followed by the addition of $\mathrm{H}_{2} \mathrm{O}_{2}(200 \mu \mathrm{M})$. The reaction was stopped after $10 \mathrm{~min}$ by addition of TCA $(10 \%, \mathrm{v} / \mathrm{v})$. Subsequently, 0.2 volume of ferrous ammonium sulfate $(10 \mathrm{mM})$ and 0.1 volume of potassium thiocyanate $(2.5 \mathrm{M})$ were added. Absorbance of the red colored complex was spectrophotometrically measured at $480 \mathrm{~nm}$. The amount of residual $\mathrm{H}_{2} \mathrm{O}_{2}$ remaining in the reaction was calculated from a standard calibration curve prepared by using known concentrations of $\mathrm{H}_{2} \mathrm{O}_{2}$. Trx-dependent peroxidase reactions were performed in a $50 \mu \mathrm{l}$ reaction mixture containing HEPES-NaOH (50 mM, pH 7.0), E. coli thioredoxin A (TrxA, $5 \mu \mathrm{M})$, E. coli thioredoxin reductase (TR, $0.5 \mu \mathrm{M}$ ), NADPH $(0.25 \mathrm{mM})$, Prx Protein or its mutant variants (0.05-1 $\mu \mathrm{g})$, and $\mathrm{H}_{2} \mathrm{O}_{2}(200 \mu \mathrm{M})$. For GSH-dependent peroxidase activity, the typical reaction mixture contained HEPES/NaOH (50 mM, pH 7.0), NADPH (0.25 mM), glutathione reductase $(\mathrm{GR}, 0.2 \mu \mathrm{M})$, Prx protein $(1 \mu \mathrm{g})$ and reduced glutathione (GSH, $5 \mathrm{mM})$. The reaction was started by addition of $100 \mu \mathrm{M}$ peroxide substrate. The residual amount of peroxide was determined by ferrithiocyanate system as mentioned above. NTRCdependent peroxidase activity of Alr4641 with different peroxide substrates was determined as described by Pascual et al. (2011) [32]. 


\section{Protein electrophoresis, Western blotting and immunodetection}

Purified Alr4641, Alr4641C56S and Alr4641C178S were resolved electrophoretically by $12 \%$ SDS-PAGE with or without DTT $(10 \mathrm{mM})$. These three proteins were also resolved by native PAGE and stained with CBB. Total cellular proteins from Anabaena cultures were extracted using Laemmli's buffer [50] and electrophoretically separated by $12 \%$ SDS-PAGE. The gel was electroblotted on to a nitrocellulose membrane as described earlier [51]. In case of native PAGE, for efficient transfer, the gel was immersed in $1 \mathrm{X}$ SDS-PAGE running buffer, incubated at $70^{\circ} \mathrm{C}$ for $30 \mathrm{~min}$ and electroblotted on to the nitrocellulose membrane. Immunodetection was carried out with the Alr4641 antiserum.

\section{Pull down assay}

In the pull-down experiment, His-tagged NTRC (500 $\mu \mathrm{g})$ was allowed to bind to Ni-NTA agarose slurry $(100 \mu \mathrm{l})$ in assay buffer (50 mM Tris, $200 \mathrm{mM} \mathrm{NaCl}, 5 \mathrm{mM}$ immidazole) for $2 \mathrm{~h}$ at $4^{\circ} \mathrm{C}$, followed by washing with same buffer to remove the unbound NTRC. Cytosolic extract of An4641 $1^{+}$(800 $\mu \mathrm{g}$ protein) was incubated with NTRCbound Ni-NTA agarose overnight at $4^{\circ} \mathrm{C}$ with constant rocking. In the control experiment, only Ni-NTA agarose was incubated with cytosolic fraction of An4641 $1^{+}$In both the cases, agarose was centrifuged at $5000 \mathrm{~g}$ for $5 \mathrm{~min}$ at $4^{\circ} \mathrm{C}$, washed thrice with the assay buffer, boiled with cracking buffer and resolved on 12.5\% SDS-PAGE. The gel was transferred on to a nitrocellulose membrane and probed with anti-Alr4641 antibody.

\section{Co-Immuno-precipitation}

For co-immuno-precipitation, the His-tagged NTRC (50 $\mu \mathrm{g})$ was allowed to incubate with His-tagged Alr4641 (50 $\mu \mathrm{g})$ in co-immunoprecipitation buffer $(50 \mathrm{mM}$ Tris- $\mathrm{Cl} \mathrm{pH}$ 7.5, 15 mM EDTA, $100 \mathrm{mM} \mathrm{NaCl}, 0.1 \%$ Triton X-100 and protease inhibitor cocktail obtained from Sigma) at $4^{\circ} \mathrm{C}$ in duplicate. To one vial, Alr4641 antiserum was added and the components were allowed to interact for $6 \mathrm{~h}$ at $4^{\circ} \mathrm{C}$ with constant shaking. No antibody was added to the other vial (negative control). After that, a slurry of protein-G agarose beads $(50 \mu \mathrm{l})$ was added to both the vials and these were kept shaking overnight at $4^{\circ} \mathrm{C}$. Next day, beads were precipitated by centrifuging at $1200 \mathrm{~g}$ for $5 \mathrm{~min}$ at $4^{\circ} \mathrm{C}$ and washed thrice with the co-immuno-precipitation buffer. Subsequently, sample buffer was added to beads and the proteins extracted by boiling. The extracted proteins were separated on SDS-polyacrylamide (12.5\%) gels, and visualized by staining.

\section{Surface plasmon resonance (SPR) analysis}

Autolab Esprit SPR system was used for surface plasmon resonance analysis with bare gold sensor chip. At $20^{\circ} \mathrm{C}$, about 250 response units of Alr4641 was loaded onto the bare gold chip employing the EDC-NHS chemistry (Autolab ESPIRIT User manual SPR) followed by extensive washing with buffer $\mathrm{H}$ (10 mM HEPES, $100 \mathrm{mM}$ $\mathrm{NaCl}, \mathrm{pH}$ 7.5). Different concentrations (4.33, 8.66, 10.39 and $12.99 \mu \mathrm{M}$ ) of the NTRC protein were injected onto the Alr4641-bound sensor chip at $33.3 \mu \mathrm{L} \mathrm{min}{ }^{-1}$ flow rate in independent experiments. The NTRC was allowed to interact with the immobilized Alr4641 for $300 \mathrm{~s}$ before washing off with buffer $\mathrm{H}$. The data were processed and equilibrium constant $\left(\mathrm{K}_{\mathrm{D}}\right)$ was calculated using Autolab kinetic evaluation software (V5.4) provided with the instrument.

\section{Gel retardation assays (GRA)}

Primers 4641Prom_GRAFwd and 4641Prom_GRARev were annealed to form a 39-bp dsDNA (i.e. alr4641 promoter), which was used for the gel shift assays with the purified FurA protein. The end labeling of DNA fragments with digoxygenin (DIG) and the subsequent GRA, in the presence of the non-specific competitor poly ( $\mathrm{dI}-\mathrm{dC})$, was performed as described by the manufacturer (Roche).

\section{Metal catalyzed oxidation (MCO) assay for antioxidant activity}

The plasmid DNA (pBluescript, $1 \mu \mathrm{g}$ ) was subjected to MCO by incubating $\mathrm{FeCl}_{3}(20 \mu \mathrm{M})$ and DTT $(5 \mathrm{mM})$ at room temperature for $30 \mathrm{~min}$. Purified proteins $(2-20 \mu \mathrm{g})$ were added to the reaction mixture and further incubated for $4 \mathrm{~h}$. Subsequently, DNA integrity was assessed by electrophoresis of reaction samples on agarose $(0.8 \%$, TBE, pH 7) gels.

\section{Oxidation and reduction of the Alr4641 protein}

The purified Alr4641 protein was oxidized with $\mathrm{H}_{2} \mathrm{O}_{2}$ $(10 \mathrm{mM})$ for $30 \mathrm{~min}$ or reduced by addition of DTT (5 mM). The samples were analyzed for chaperone activity as described earlier or resolved on Native PAGE and visualized by $\mathrm{CBB}$ staining.

\section{Northern blotting-hybridization and dot blot analysis}

Isolation of Anabaena PCC7120 total RNA and subsequent Dot blot or Northern blotting-hybridization analysis with the alr4641 DIG-labeled DNA probe was performed as described earlier [52].

\section{Rapid amplification of cDNA ends (RACE)}

The total RNA isolated from the wild-type Anabaena PCC7120 cells stressed with $\mathrm{H}_{2} \mathrm{O}_{2}$, for $1 \mathrm{~h}$ was treated with DNase I and re-purified using commercial spin columns (Nucleospin RNA clean-up XS, Macherey Nagel). The reverse primer EXTERN-4641RACE-Rev (Additional file 6) was employed for cDNA synthesis. Tailing of cDNA using dATP and terminal transferase, the subsequent PCR 
with oligo dT-anchor primer and an internal gene-specific primer (INTER-4641RACE-Rev) was performed exactly as described (5'/3' RACE kit, $2^{\text {nd }}$ Generation, Roche).

\section{Construction of GFP promoter}

A 600-bp DNA fragment (upstream of the alr4641 gene) that contained the alr4641 promoter was amplified with suitable primers and cloned just upstream of $g f p$ (reporter gene) in pAM1956 employing the restriction enzymes $K p n I$ and SacI (construct named as pAM4641prom). This construct was conjugated into Anabaena PCC7120 and exconjugants (An4641 prom) were selected on BG-11/ $\mathrm{N}^{+}$ plates containing neomycin $\left(25 \mu \mathrm{g} \mathrm{ml}^{-1}\right)$ and subjected to microscopic analysis.

\section{Heterocyst isolation}

Anabaena PCC7120 was grown aerobically in nitrogenfree BG-11 liquid medium. Heterocysts were isolated from whole filaments using modified protocol as described by Cha et al., 2007 [44]. Anabaena culture was harvested and subjected to several freeze-thaw cycles in Tris-buffer (20 mM Tris, $1 \mathrm{mM}$ EDTA, $\mathrm{pH}$ 7.4). After centrifugation for $5 \mathrm{~min}$ at $1000 \mathrm{~g}$, the sedimented cells were suspended in the same buffer, glass beads $(600 \mu \mathrm{M})$ were added and the suspension was vortexed for $2 \mathrm{~min}$. Subsequently, the suspension was centrifuged at $150 \mathrm{~g}$ for 5 min to obtain heterocysts in the supernatant. Enrichment of greenish yellow heterocysts was achieved by repeatedly washing (7-8 times) and centrifuging ( $150 \mathrm{~g}$, 5 min) the heterocyst pellet.

\section{Construction of pAM4641 plasmid and over-expression of} Alr4641 protein in Anabaena PCC7120

The alr4641 DNA fragment ( 0.66-kb) from pET4641 was subcloned, downstream of the strong $\mathrm{P}_{p s b A 1}$ promoter, into the pFPN vector [53] employing the restriction enzymes NdeI and BamHI (plasmid called pFPN4641). Subsequently, the alr4641 gene along with the $\mathrm{P}_{p s b A 1}$ promoter was transferred as a SalI-XmaI fragment from pFPN4641 to appropriately digested E. coli/Anabaena shuttle vector pAM1956 [54] to obtain pAM4641. Using a conjugal E. coli donor [HB101 (pRL623 + pRL443)], pAM4641 was conjugated into Anabaena PCC7120 as described earlier [55]. Exconjugants were selected on BG-11/ $\mathrm{N}^{+}$plates containing neomycin $\left(25 \mu \mathrm{g} \mathrm{ml}^{-1}\right)$ and repeatedly subcultured. The transformed Anabaena strain thus obtained (designated An4641 $1^{+}$) was maintained on BG-11/ $\mathrm{N}^{+}$plates containing neomycin.

\section{$\mathrm{CO}_{2}$ fixation}

The wild-type Anabaena PCC7120 and the recombinant An $4641^{+}$cells were subjected to $1 \mathrm{mM} \mathrm{H} \mathrm{H}_{2} \mathrm{O}_{2}$ treatment for 1 day. Culture aliquot $(200 \mu \mathrm{l})$ of the above-mentioned Anabaena cells (5-6 $\mu \mathrm{g} \mathrm{ml}^{-1}$ chlorophyll $a$ ) was incubated in white fluorescent light $\left(24 \mathrm{~W} \mathrm{~m}^{-2}\right)$ for $5 \mathrm{~min}$ and followed by addition of $\mathrm{NaH}^{14} \mathrm{CO}_{3}(20 \mathrm{mM}$, specific activity $0.5 \mathrm{mCi} \mathrm{mmol}{ }^{-1}$ ). The reaction was stopped after $10 \mathrm{~min}$ by addition of $400 \mu \mathrm{l}$ of $6 \mathrm{~N}$ acetic acid to the reaction mixture. The acid stable product was counted in a liquid scintillation counter with $0.4 \%$ BBOT [2, 5-bis (5tert-butylbenzoxazole-2-yl) thiophen] dissolved in a solution containing toluene and absolute ethanol (v/v, 65:35). The experiment was performed twice with three replicate samples each time.

\section{DCHFDA assay}

The content of the reactive oxygen species (ROS) in Anabaena strains treated with $\mathrm{H}_{2} \mathrm{O}_{2}$ for 1 day and in respective controls cells was measured with Dichlorodihydrofluorescein diacetate (DCHFDA) [56]. Briefly, DCHFDA (10 $\mu \mathrm{M}$ final concentration) was added to cells suspended in BG11 medium ( $3 \mu \mathrm{g}$ chlorophyll $a \mathrm{ml}^{-1}$ ). Cells were incubated for $20 \mathrm{~min}$ in dark at $25^{\circ} \mathrm{C}$. Fluorescence emission $\left(\lambda_{\mathrm{ex}}=\right.$ $490 \mathrm{~nm}$ and $\lambda_{\mathrm{em}}=520 \mathrm{~nm}$ ) of the control or $\mathrm{H}_{2} \mathrm{O}_{2}$ (1 mM)-treated cells was measured immediately afterwards. Experiments were repeated thrice and average values are reported.

\section{Determination of oxidative stress tolerance of An4641 strain}

Three-day-old Anabaena cultures of the wild-type Anabaena PCC7120 (WT) as well as An4641 ${ }^{+}$(in triplicates) were inoculated in a fresh growth medium at a chlorophyll a density of $3 \mu \mathrm{g} \mathrm{ml}^{-1}$ and subjected to $\mathrm{H}_{2} \mathrm{O}_{2}(1 \mathrm{mM})$ stress in tubes (without shaking) under illumination for 2 days. Growth was monitored in liquid cultures by determination of chlorophyll $a$ content [48].

\section{Bioinformatic analysis}

Amino acid sequence was analysed using BLAST (http:// blast.ncbi.nlm.nih.gov/Blast.cgi) or SMART (http://smart. embl-heidelberg.de/) algorithms [57,58]. Promoter, upstream of the transcriptional start site, was identified by a promoter search program (www.softberry.com). DNAbinding consensus sequence (GATAATGATAATCA TT ATC) of the E. coli FurA protein was used to identify corresponding sequences from DNA upstream of the alr4641 ORF using the LALIGN program (www.ch.embnet.org).

\section{Additional files}

Additional file 1: Purification of FurA and its binding with FurA binding sequence of Alr4641 promoter. (A)The FurA protein from Anabaena PCC7120 was over-expressed in E. coli and purified by affinity chromatography as described in the Methods section. After electrophoresis proteins were visualized by staining with CBB. Lane 1, mol. mass marker and lane 2, purified FurA protein $(5 \mu \mathrm{g}$ ). (B) Gel shift assays with FurA. The DNA fragment corresponding to the FurA binding site (Figure 2B) was 
end-labeled with DIG and employed for EMSA with the FurA protein in the presence of non-specific competitor poly (dl-dC). The samples were electrophoretically resolved, electro-blotted onto nylon membrane and probed with anti DIG antiserum. The position of DNA-protein complex is indicated by an arrow.

Additional file 2: Tryptophan fluorescence (Ex-295nm) spectra of the wild-type Alr4641, Alr4641C56S and Alr4641C178S proteins. Emission peaks were at the same position.

Additional file 3: Surface plasmon resonance analysis showing interaction of Alr4641 with NTRC. Alr4641 was loaded onto the bare gold chip employing the EDC-NHS chemistry. Different concentrations $(4.33,8.66,10.39$ and $12.99 \mu \mathrm{M})$ of the NTRC protein were injected onto the Alr4641-bound sensor chip at $33.3 \mu \mathrm{L} / \mathrm{min}$ flow rate in independent experiments. For each concentration, the experimental curve (solid lines) matches the calculated profile (dotted lines) for SPR curve.

Additional file 4: NTRC-dependent peroxidase activity of Alr4641. Reduction of various peroxide substrates $(100 \mu \mathrm{M}$ each, as indicated in the figure) by the Alr4641 protein in the presence of the NTRC protein was measured by monitoring the decrease in absorbance of $\mathrm{NADPH}$ at $340 \mathrm{~nm}$.

Additional file 5: List of E. coli, Anabaena strains and plasmids used in this study.

Additional file 6: List of primers used in the study.

\section{Competing interests}

The authors declare that they have no competing interests.

\section{Authors' contributions}

$A B$ conceived the study. $A B$ and $M B$ designed the experiments. $M B, A B$ and $D C$ performed the experiments, interpreted the data and wrote the paper. All authors read and approved the final manuscript.

\section{Acknowledgements}

We would like to thank Dr. S. K. Apte for constant encouragement and support during the course of this work. Expertise provided by Dr. (Mrs.) J. K. Sainis (for PAM Fluorimetry) and Dr. Subhash Bihani (for CD spectropolarimetry) is highly appreciated. Dr. Rachna Agarwal is gratefully acknowledged for helpful discussion during the preparation of the manuscript.

Received: 20 July 2014 Accepted: 29 January 2015

Published online: 21 February 2015

\section{Reference}

1. Cui H, Wang Y, Wang Y, Qin S. Genome-wide analysis of putative peroxiredoxin in unicellular and filamentous cyanobacteria. BMC Evol Biol. 2012;12:220.

2. Dietz KJ. Peroxiredoxins in plants and cyanobacteria. Antioxid Redox Signal. 2011;15:1128-59.

3. Wood ZA, Schröder E, Robin-Harris J, Poole LB. Structure, mechanism and regulation of peroxiredoxins. Trends Biochem Sci. 2003;28:32-40.

4. Edgar RS, Green EW, Zhao Y, van Ooijen G, Olmedo M, Qin X, et al. Peroxiredoxins are conserved markers of circadian rhythms. Nature. 2012;485:459-64

5. Chae HZ, Uhm TB, Rhee SG. Dimerization of thiol-specific antioxidant and the essential role of cysteine 47. Proc Natl Acad Sci U S A. 1994;91:7022-6.

6. Biteau B, Labarre J, Toledano MB. ATP-dependent reduction of cysteinesulphinic acid by S. cerevisiae sulphiredoxin. Nature. 2003;425:980-4.

7. Wood ZA, Poole LB, Karplus PA. Peroxiredoxin evolution and the regulation of hydrogen peroxide signaling. Science. 2003;300:650-3.

8. Pascual MB, Mata-Cabana A, Florencio FJ, Lindahl M, Cejudo FJ. Overoxidation of 2-Cys peroxiredoxin in prokaryotes: cyanobacterial 2-Cys peroxiredoxins sensitive to oxidative stress. J Biol Chem. 2010;285:34485-92.

9. Baier M, Dietz KJ. Protective function of chloroplast 2-cysteine peroxiredoxin in photosynthesis. Evidence from transgenic Arabidopsis. Plant Physiol. 1999:19:1407-14.

10. Muthuramalingam M, Seidel T, Laxa M, de Miranda SM N, Gärtner F, Ströher $E$, et al. Multiple redox and non-redox interactions define 2-Cys peroxiredoxin as a regulatory hub in the chloroplast. Mol Plant. 2009;2:1273-88.
11. Pulido P, Spínola MC, Kirchsteiger K, Guinea M, Pascual MB, Sahrawy M, et al. Functional analysis of the pathways for 2-Cys peroxiredoxin reduction in Arabidopsis thaliana chloroplasts. J Exp Bot. 2010;61:4043-54.

12. Kim MD, Kim YH, Kwon SY, Jang BY, Lee SY, Yun DJ, et al. Overexpression of 2-cysteine peroxiredoxin enhances tolerance to methyl viologen-mediated oxidative stress and high temperature in potato plants. Plant Physiol Biochem. 2011:49:891-7.

13. Kim MD, Kim YH, Kwon SY, Jang BY, Lee SY, Yun DJ, et al. A novel oxidative stress-inducible peroxidase promoter from sweetpotato: molecular cloning and characterization in transgenic tobacco plants and cultured cells. Plant Mol Biol. 2003;51:831-8.

14. Hosoya-Matsuda N, Motohashi K, Yoshimura H, Nozaki A, Inoue K, Ohmori $M$, et al. Anti-oxidative stress system in cyanobacteria. Significance of type II peroxiredoxin and the role of 1-Cys peroxiredoxin in Synechocystis sp. strain PCC 6803. J Biol Chem. 2005;280:840-6.

15. Perelman A, Uzan A, Hacohen D, Schwarz R. Oxidative stress in Synechococcus sp. strain PCC 7942: various mechanisms for $\mathrm{H} 2 \mathrm{O} 2$ detoxification with different physiological roles. J Bacteriol. 2003;185:3654-60.

16. Limauro D, Pedone E, Galdi I, Bartolucci S. Peroxiredoxins as cellular guardians in Sulfolobus solfataricus: characterization of Bcp1, Bcp3 and Bcp4. FEBS J. 2008;275:2067-77.

17. Bang YJ, Oh MH, Choi SH. Distinct characteristics of two 2-Cys peroxiredoxins of Vibrio vulnificus suggesting differential roles in detoxifying oxidative stress. J Biol Chem. 2010;287:42516-24.

18. Kang SW, Rhee SG, Chang TS, Jeong W, Choi MH. 2-Cys peroxiredoxin function in intracellular signal transduction: therapeutic implications. Trends Mol Med. 2005;11:571-8.

19. An BC, Lee SS, Lee EM, Lee JT, Wi SG, Jung HS, et al. A new antioxidant with dual functions as a peroxidase and chaperone in Pseudomonas aeruginosa. Mol Cells. 2010;29:145-51.

20. Jang HH, Kyun OL, Yong HC, Bae GJ, Soo KP, Jin HP, et al. Two enzymes in one: two yeast peroxiredoxins display oxidative stress-dependent switching from a peroxidase to a molecular chaperone function. Cell. 2004;117:625-35.

21. König J, Baier M, Horling F, Kahmann U, Harris G, Schürmann P, et al. The plant-specific function of 2-Cys peroxiredoxin-mediated detoxification of peroxides in the redox-hierarchy of photosynthetic electron flux. Proc Natl Acad Sci U S A. 2002;99:5738-43.

22. Brock TD. Evolutionary and ecological aspects of cyanophytes. In: Carr NG, Whitton BA, editors. The biology of blue-green algae. Oxford: Blackwell; 1973. p. 487-500.

23. Fay P. Oxygen relations of nitrogen fixation in cyanobacteria. Microbiol Rev. 1992:56:340-73.

24. Venkataraman GS. Algal inoculation in rice field. In: Brady NC, editor. Nitrogen and rice. Los Banos, Philippines: International Rice Research Institute; 1979.

25. Banerjee M, Ballal A, Apte SK. A novel glutaredoxin domain-containing peroxiredoxin 'All1541' protects the N2-fixing cyanobacterium Anabaena PCC7120 from oxidative stress. Biochem J. 2012;442:671-80.

26. Tailor V, Ballal A. Over-expression of Alr4642, a novel Prx-like peroxiredoxin, defends the cyanobacterium Anabaena PCC7120 from oxidative stress. J Appl Phycol. 2015. doi:10.1007/s10811-014-0503-3.

27. Banerjee M, Ballal A, Apte SK. Mn-catalase (Alr0998) protects the photosynthetic, nitrogenfixing cyanobacterium Anabaena PCC7120 from oxidative stress. Environ Microbiol. 2012;14:2891-900.

28. Bihani S, Chakravarty D, Ballal A. Purification, crystallization, and preliminary crystallographic analysis of KatB, a manganese catalysis from Anabaena PCC7120. Acta Crystallogr Sect F Struct Biol Cryst Commun. 2013; 69:1299-302.

29. Banerjee M, Raghavan PS, Ballal A, Rajaram H, Apte SK. Oxidative stress management in the filamentous, heterocystous, diazotrophic cyanobacterium, Anabaena PCC7120. Photosynth Res. 2013;118:59-70.

30. Kaneko T, Nakamura Y, Wolk CP, Kuritz T, Sasamoto S, Watanabe A, et al. Complete genomic sequence of the filamentous nitrogen-fixing cyanobacterium Anabaena sp. strain PCC 7120. DNA Re. 2001;8:205-13.

31. Latifi A, Ruiz M, Jeanjean R, Zhang CC. PrxQ-A, a member of the peroxiredoxin $\mathrm{Q}$ family, plays a major role in defense against oxidative stress in the cyanobacterium Anabaena sp. strain PCC7120. Free Radic Biol Med. 2007:42:424-31.

32. Pascual MB, Mata-Cabana A, Florencio FJ, Lindahl M, Cejudo FJ. A comparative analysis of the NADPH thioredoxin reductase C-2-Cys peroxiredoxin system from plants and cyanobacteria. Plant Physiol. 2011;155:1806-16.

33. Kumsta C, Jakob U. Redox-regulated chaperones. Biochemistry. 2009;48:4666-76. 
34. González A, Bes MT, Peleato ML, Fillat MF. Unraveling the regulatory function of FurA in Anabaena sp. PCC7120 through 2-D DIGE proteomic analysis. J Proteomics. 2011;74:660-71.

35. Stork T, Michel KP, Pistorius EK, Dietz KJ. Bioinformatic analysis of the genomes of the cyanobacteria Synechocystis sp. PCC 6803 and Synechococcus elongatus PCC 7942 for the presence of peroxiredoxins and their transcript regulation under stress. J Exp Bot. 2005;56:3193-206.

36. Saccoccia F, Di Micco P, Boumis G, Brunori M, Koutris I, Miele AE, et al. Moonlighting by different stressors: crystal structure of the chaperone species of a 2-Cys peroxiredoxin. Structure. 2012;20:429-39.

37. König J, Galliardt H, Jütte P, Schäper S, Dittmann L, Dietz KJ. The conformational bases for the two functionalities of 2-cysteine peroxiredoxins as peroxidase and chaperone. J Exp Bot. 2013;64:3483-97.

38. Alliegro MC. Effects of dithiothreitol on protein activity unrelated to thiol-disulfide exchange: for consideration in the analysis of protein function with Cleland's reagent. Anal Biochem. 2000;282:102-6.

39. Gentz PM, Blatch GL, Dorrington RA. Dimerization of the yeast eukaryotic translation initiation factor $5 \mathrm{~A}$ requires hypusine and is RNA dependent. FEBS J. 2009;276:695-706

40. Boileau C, Eme L, Brochier-Armanet C, Janicki A, Zhang CC, Latifi A. A eukaryotic-like sulfiredoxin involved in oxidative stress responses and in the reduction of the sulfinic form of 2-Cys peroxiredoxin in the cyanobacterium Anabaena PCC7120. New Phytol. 2011;191:1108-18.

41. Wolk CP. Heterocyst formation. Annu Rev Genet. 1996;30:59-78.

42. Asada K. The water-water cycle in chloroplasts: scavenging of active oxygens and dissipation of Excess Photons. Annu Rev Plant Physiol Plant Mol Biol. 1999;50:601-39.

43. Thorneley RN, Ashby GA. Oxidation of nitrogenase iron protein by dioxygen without inactivation could contribute to high respiration rates of Azotobacter species and facilitate nitrogen fixation in other aerobic environments. Biochem J. 1989;261:181-7.

44. Cha M, Hong SK, Kim IH. Four thiol peroxidases contain a conserved GCT catalytic motif and act as a versatile array of lipid peroxidases in Anabaena sp. PCC7120. Free Radic Biol Med. 2007;42:1736-48.

45. Drábková M, Admiraal W, Marsálek B. Combined exposure to hydrogen peroxide and light-selective effects on cyanobacteria, green algae, and diatoms. Environ Sci Technol. 2007:41:309-14.

46. Drábková M, Matthijs HCP, Admiraal W, Marsalek B. Selective effects of H2O2 on cyanobacterial photosynthesis. Photosynthetica. 2007;45:363-9.

47. Qian H, Yu S, Sun Z, Xie X, Liu W, Fu Z. Effects of copper sulfate, hydrogen peroxide and $\mathrm{N}$-phenyl-2-naphthylamine on oxidative stress and the expression of genes involved photosynthesis and microcystin disposition in Microcystis aeruginosa. Aquat Toxicol. 2010;99:405-12.

48. Mackinney G. Absorption of light by chlorophyll solutions. J Biol Chem. 1941;140:315-22

49. Ballal A, Apte SK. Characterization of a response regulator protein that binds to Anabaena sp. strain L-31 kdp-promoter region. Arch Biochem Biophys. 2008;474:65-71.

50. Laemmli UK. Cleavage of structural proteins during the assembly of the head of bactetiophage T4. Nature. 1970;227:680-5.

51. Alahari A, Apte SK. Pleiotropic effects of potassium deficiency in a heterocystous, nitrogen-fixing cyanobacterium, Anabaena torulosa. Microbiol. 1998;144:1557-63.

52. Ballal A, Apte SK. Differential expression of the two kdp operons in the nitrogen-fixing cyanobacterium Anabaena sp. strain L-31. Appl Environ Microbiol. 2005;79:5297-303.

53. Chaurasia A, Parasnis A, Apte SK. An integrative expression vector for strain improvement and environmental applications of the nitrogen fixing cyanobacterium, Anabaena sp. strain PCC7120. J Microbiol Meth. 2008;73:133-41.

54. Yoon HS, Golden JW. Heterocyst pattern formation controlled by a diffusible peptide. Science. 1998;282:935-8.

55. Elhai J, Vepritskiy A, Muro-Pastor AM, Flores E, Wolk CP. Reduction of conjugal transfer efficiency by three restriction activities of Anabaena sp. strain PCC 7120. J Bacteriol. 1997;179:1998-2005.
56. He YY, Hader DP. UV-B induced formation of reactive oxygen species and oxidative damage of the cyanobacterium Anabaena sp.: protective effects of ascorbic acid and N-acetyl-I-cysteine. J Photochem Photobiol B: Biol. 2002;66:115-24.

57. Altschul SF, Gish W, Miller W, Myers EW, Lipman DJ. Basic local alignment search tool. J Mol Biol. 1990;215:403-10.

58. Schultz J, Milpetz F, Bork P, Ponting CP. SMART, a simple modular architecture research tool: identification of signaling domains. Proc Natl Acad Sci USA. 1998;95:5857-64.

\section{Submit your next manuscript to BioMed Central and take full advantage of:}

- Convenient online submission

- Thorough peer review

- No space constraints or color figure charges

- Immediate publication on acceptance

- Inclusion in PubMed, CAS, Scopus and Google Scholar

- Research which is freely available for redistribution

Submit your manuscript at www.biomedcentral.com/submit 